\title{
Identification of a New Inborn Error in Bile Acid Synthesis: Mutation of the Oxysterol $7 \alpha$-Hydroxylase Gene Causes Severe Neonatal Liver Disease
}

\author{
Kenneth D.R. Setchell, ${ }^{\star}$ Margrit Schwarz,, Nancy C. O’Connell, ${ }^{\star}$ Erik G. Lund, Daphne L. Davis, ${ }^{\ddagger}$ Richard Lathe, ${ }^{\S}$ \\ Henry R. Thompson, "R. Weslie Tyson, "Ronald J. Sokol, and David W. Russell \\ *Clinical Mass Spectrometry Center, Department of Pediatrics, Children’s Hospital Medical Center, Cincinnati, Ohio 45229; ${ }^{\ddagger}$ Department \\ of Molecular Genetics, University of Texas Southwestern Medical Center, Dallas, Texas 75235; ${ }^{\circledR}$ Centre for Genome Research, University \\ of Edinburgh, Edinburgh, Scotland; and $\|$ Pediatric Liver Center, Section of Pediatric Gastroenterology, Hepatology and Nutrition, The \\ Children's Hospital, University of Colorado Health Sciences Center, Denver, Colorado 80218
}

\begin{abstract}
We describe a metabolic defect in bile acid synthesis involving a deficiency in $7 \alpha$-hydroxylation due to a mutation in the gene for the microsomal oxysterol $7 \alpha$-hydroxylase enzyme, active in the acidic pathway for bile acid synthesis. The defect, identified in a 10-wk-old boy presenting with severe cholestasis, cirrhosis, and liver synthetic failure, was established by fast atom bombardment ionization-mass spectrometry, which revealed elevated urinary bile acid excretion, a mass spectrum with intense ions at $\mathrm{m} / \mathrm{z} 453$ and $\mathrm{m} / \mathrm{z} 510$ corresponding to sulfate and glycosulfate conjugates of unsaturated monohydroxy-cholenoic acids, and an absence of primary bile acids. Gas chromatography-mass spectrometric analysis confirmed the major products of hepatic synthesis to be $3 \beta$-hydroxy-5-cholenoic and $3 \beta$-hydroxy5 -cholestenoic acids, which accounted for $96 \%$ of the total serum bile acids. Levels of 27-hydroxycholesterol were $>4,500$ times normal. The biochemical findings were consistent with a deficiency in $7 \alpha$-hydroxylation, leading to the accumulation of hepatotoxic unsaturated monohydroxy bile acids. Hepatic microsomal oxysterol $7 \alpha$-hydroxylase activity was undetectable in the patient. Gene analysis revealed a cytosine to thymidine transition mutation in exon 5 that converts an arginine codon at position 388 to a stop codon. The truncated protein was inactive when expressed in 293 cells. These findings indicate the quantitative importance of the acidic pathway in early life in humans and define a further inborn error in bile acid synthesis as a metabolic cause of severe cholestatic liver disease. (J. Clin. Invest. 1998. 102: 1690-1703.) Key words: cholestasis • mass spectrometry • genetics • cholesterol metabolism
\end{abstract}

This study was presented in part at the Annual Meeting of the American Gastroenterological Association, Digestive Diseases Week, Washington DC, 11-14 May 1997 and was published in abstract form (1997. Gastroenterology. 112:A1379).

Address correspondence to Kenneth D.R. Setchell, Ph.D., Clinical Mass Spectrometry, Children's Hospital Medical Center, 3333 Burnet Avenue, Cincinnati, OH 45229. Phone: 513-636-4548; FAX: 513-636-7853; E-mail: setck0@chmcc.org

Received for publication 2 February 1998 and accepted in revised form 1 September 1998.

J. Clin. Invest.

(C) The American Society for Clinical Investigation, Inc. 0021-9738/98/11/1690/14 \$2.00

Volume 102, Number 9, November 1998, 1690-1703

http://www.jci.org

\section{Introduction}

Inborn errors in bile acid synthesis are now a recognized category of metabolic liver disease $(1,2)$. Specific defects have been identified in the enzymes catalyzing reactions responsible for changes to the steroid nucleus $(3,4)$ and side chain $(5-9)$ of cholesterol and its intermediates in the pathway leading to the formation of cholic and chenodeoxycholic acids (10). These familial conditions are clinically manifest as syndromes of progressive cholestatic liver disease, neurological disease, and fat-soluble vitamin malabsorption $(1,2)$. Early diagnosis is important because patients with these disorders can be successfully treated by oral administration of cholic acid; normalization in serum liver enzymes and bilirubin and resolution of the histologic lesion are consistent responses to bile acid therapy $(1,2,11,12)$, and the need for liver transplantation in most cases can be circumvented.

Recognition of defects in bile acid synthesis has relied upon mass spectrometric analysis of the urine and serum to establish an absence or marked reduction in synthesis of the normal primary bile acids, cholic and chenodeoxycholic acids, concomitant with the presence of excessive amounts of atypical bile acids and sterols that are synthesized as a consequence of the enzyme deficiency (13). There has been relatively little success in understanding the genetic basis and molecular biology of these disorders, because with few exceptions the genes responsible for most of these enzymes have yet to be identified, sequenced, and cloned (10).

The synthesis of primary bile acids from cholesterol occurs via two pathways: the classical neutral pathway involving cholesterol $7 \alpha$-hydroxylase and the acidic pathway, which uses a distinct microsomal oxysterol $7 \alpha$-hydroxylase (14-20). The expression of the oxysterol $7 \alpha$-hydroxylase, and hence acidic pathway, is developmentally regulated in mice $(21,22)$. When active, this pathway partially compensates for the neutral pathway in animals lacking the cholesterol $7 \alpha$-hydroxylase gene (21), a finding that indicates the quantitative importance of the acidic pathway for bile acid synthesis. The quantitative contribution of these two pathways to total bile acid synthesis has also been measured in the rat (20) and the results reinforce the view that the acidic pathway, at least in rodents, is a major pathway for bile acid synthesis in the face of reduced cholesterol $7 \alpha$-hydroxylase activity.

We now describe for the first time in a human a metabolic defect in bile acid synthesis involving a deficiency in $7 \alpha-$ hydroxylation that represents a further cause of severe neonatal cholestatic liver disease. The biochemical presentation of this new inborn error features almost exclusively the formation of highly cholestatic and hepatotoxic monohydroxy-bile acids with a $3 \beta$-hydroxy- $\Delta^{5}$ ring structure. Molecular studies establish this defect to be due to mutation of the oxysterol $7 \alpha$-hydrox- 
ylase gene (symbol $C Y P 7 B 1$ ). These findings highlight the quantitative importance of the acidic pathway for bile acid synthesis in early human life.

\section{Methods}

\section{Clinical history of patient JC}

The patient was a Hispanic male infant born at term after an uneventful pregnancy by a vaginal delivery with a birth weight of $7 \mathrm{lb} .12 \mathrm{oz}$. $(3.52 \mathrm{~kg})$. The patient's parents were first cousins, both from the same small village in Mexico. This was the second pregnancy; the first resulted in a healthy male infant who was $2.5 \mathrm{yr}$ of age at the time the proband presented. The patient developed jaundice at $6 \mathrm{~d}$ of age (total serum bilirubin $18.6 \mathrm{mg} / \mathrm{dl}$ ), which resolved with phototherapy. During week 6 of life he intermittently passed acholic stools; jaundice returned at 8 wk of age. At 10 wk of age, bright red blood was passed per rectum and a spontaneous episode of epistaxis occurred. The patient was then referred to the Children's Hospital in Denver for evaluation. On physical examination, the patient was alert and icteric with height and weight between the 25th and 50th percentiles. A right scleral hemorrhage was present and nares were crusted with blood, but not actively bleeding. There were no dysmorphic features or cardiac murmur, and neurological examination was normal. The liver was firm and $3 \mathrm{~cm}$ below the right costal margin and the spleen tip was palpable. Ascites, spider hemangiomata, bruising, and edema were absent.

Initial laboratory studies revealed serum AST 440 IU/liter (normal 20-60), ALT 160 IU/liter (normal 7-46), alkaline phosphatase 1,384 IU/liter (normal 110-460), total/direct bilirubin $8.4 / 4.8 \mathrm{mg} / \mathrm{dl}$ (normal < 1.0), prothrombin time $41 \mathrm{~s}$ (normal 12.4-14.4), and blood ammonia $37 \mu \mathrm{mol} /$ liter (normal 29-57). Serum GGT was 14 IU/liter, cholesterol was $101 \mathrm{mg} / \mathrm{dl}$, and CBC was normal. Evaluations for viral infections, alpha-1-antitrypsin deficiency, hereditary tyrosinemia, cystic fibrosis, hypopituitarism, and iron storage disease were normal or negative. Serum $\alpha$-tocopherol concentration was $5.5 \mu \mathrm{g} / \mathrm{ml}$ (normal 3.8-15.5), $\alpha$-tocopherol: total serum lipids ratio was 1.07 (normal $>0.6 \mathrm{mg} / \mathrm{g}$ ), serum retinol $6.0 \mu \mathrm{g} / \mathrm{dl}$ (normal 19-77), and retinol binding protein was $0.7 \mathrm{mg} / \mathrm{dl}$ (normal 1.0-5.0). Abdominal ultrasonography showed a small gallbladder, no choledochal cyst, no dilatation of bile ducts, and bilateral enlarged kidneys without hydronephrosis. Hepatobiliary scintigraphy with iminodiacetic acid showed delayed hepatic clearance and no biliary excretion. Parenteral vitamin K treatment led to a substantial reduction in the prothrombin time to 19.1 s. Percutaneous liver biopsy (see Results) performed after correction of coagulopathy suggested biliary tract obstruction. The patient then underwent an exploratory laparotomy which showed an enlarged, firm, green liver, a normal gallbladder containing yellow bile, and a normal biliary system was seen on an intraoperative cholangiogram performed through the gallbladder. Urine and serum were shipped to Cincinnati for evaluation of bile acid synthetic defects.

The patient was treated with a medium chain triglyceride-containing formula, fat-soluble vitamin supplementation (phytonadione, 25-hydroxy-vitamin D, D- $\alpha$-tocopheryl PEG-1000 succinate), and ursodeoxycholic acid (UDCA) ${ }^{1}$ at $15 \mathrm{mg} / \mathrm{kg}$ body wt/d (Fig. 1). UDCA therapy was terminated after $10 \mathrm{~d}$ because of a marked increase in serum bilirubin and aminotransferases. After the recognition of a defect in primary bile acid synthesis, the patient was then treated with oral cholic acid at $15 \mathrm{mg} / \mathrm{kg}$ body wt/d. There was no clinical response

1. Abbreviations used in this paper: $\Delta^{5}$, unsaturation (double bond) in the molecule at the carbon position designated by the superscript, i.e., 5-ene; FAB-MS, fast atom bombardment ionization-mass spectrometry; GC-MS, gas chromatography-mass spectrometry; Me-TMS, methyl ester-trimethylsilyl; MU, methylene unit; UDCA, ursodeoxycholic acid. after $49 \mathrm{~d}$ of cholic acid therapy with continued deterioration of hepatic synthetic function (Fig. 1). Because of poor weight gain, progressive hepatosplenomegaly, hypoalbuminemia, and coagulopathy, the patient underwent orthotopic liver transplantation from a cadaver donor at $4.5 \mathrm{mo}$ of age. Immunosuppression included cyclosporine, corticosteroids, and azathioprine. Acute allograft rejection occurred on day 9 after transplant and responded to large intravenous corticosteroid bolus therapy. Neutropenia developed on day 10 and was followed by Pseudomonas aeruginosa sepsis and ecthyma gangrenosum of the buttocks on day 15 . The patient responded well to intravenous antibiotic therapy and a reduction of immunosuppression; however, on day 19 he developed sudden, rapidly progressive cerebral edema and died $24 \mathrm{~h}$ later. Autopsy revealed disseminated lymphoproliferative disease (Epstein-Barr virus-related) in all body tissues, including brain and liver, and mild allograft rejection.

During cholic acid therapy, urine and serum specimens were obtained for analytical studies of bile acid metabolites. At the time of liver transplantation, the diseased liver and bile were snap-frozen for analytical studies. DNA was prepared from peripheral white blood cells from the patient and his mother and father.

\section{Qualitative and quantitative bile acid analysis}

Total and individual bile acids were measured in urine, serum, bile, and liver tissue from the patient using a combination of fast atom bombardment ionization-mass spectrometry (FAB-MS) and gas chromatography-mass spectrometry (GC-MS) as described elsewhere (23-25).

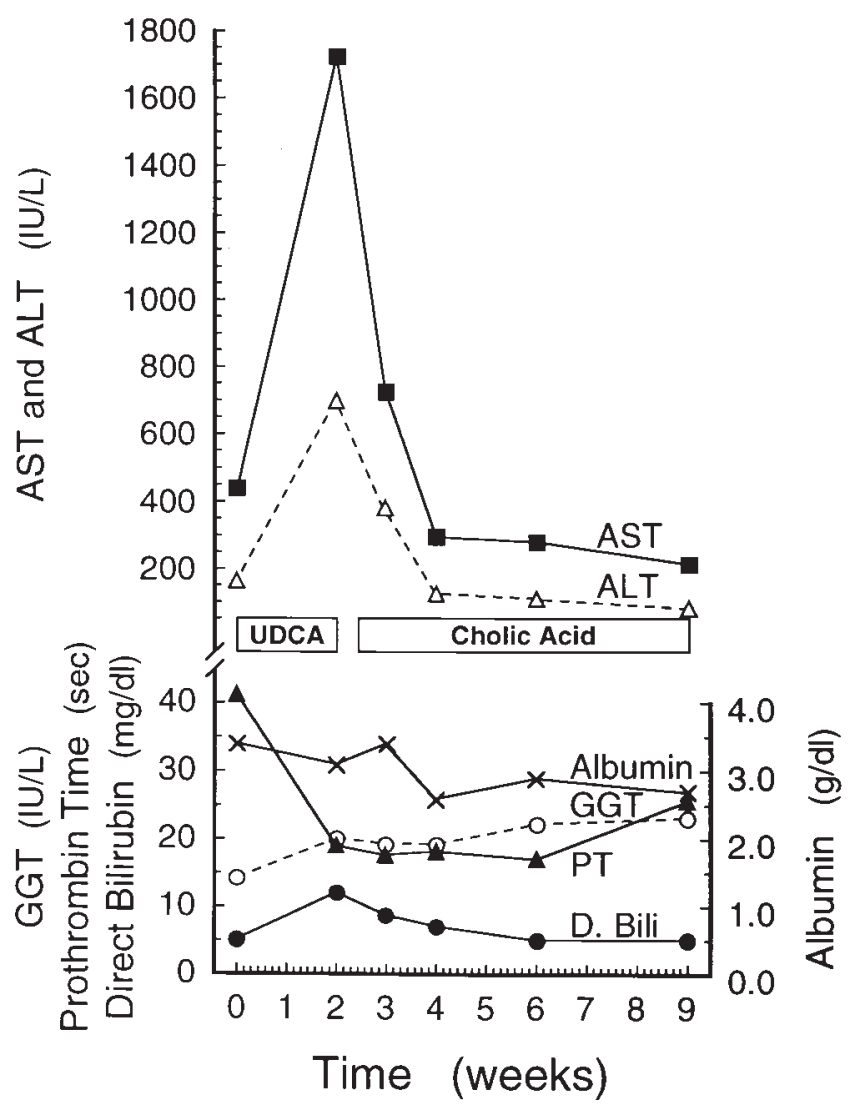

Figure 1. Changes in serum concentrations of AST, ALT, direct bilirubin, albumin, and prothrombin time in patient $\mathrm{JC}$ during therapy with UDCA $(15 \mathrm{mg} / \mathrm{kg}$ body wt/d) and cholic acid $(15 \mathrm{mg} / \mathrm{kg}$ body wt/d), up until the time of liver transplantation at $9 \mathrm{wk}$ after presentation. Initial elevated prothrombin time responded to parenteral vitamin $\mathrm{K}$ injection. Fat-soluble vitamin supplementation was continued throughout the patient's course (see text). 
Solid-phase extraction of bile acids from urine, serum, and bile. The internal standard, nordeoxycholic acid $(1-10 \mu \mathrm{g})$, was added to samples of urine $(5-10 \mathrm{ml})$, bile $(100 \mu \mathrm{l})$, and serum $(0.5-1.0 \mathrm{ml})$, and bile acids were extracted by liquid-solid extraction using reversephase octadecylsilane-bonded silica cartridges (Bond Elut- $\mathrm{C}_{18}$; Analytichem Inc., Harbor City, CA) $(26,27)$. The cartridge was washed with water, and bile acids and their conjugates were recovered from the cartridge by elution with methanol $(5 \mathrm{ml})$.

Extraction of bile acids from liver tissue. A small sample of liver $(150 \mathrm{mg})$ obtained from the patient at the time of liver transplantation was ground to a fine paste in distilled water $(20 \mathrm{ml})$ and brought to a final concentration of $80 \%$ methanol $(100 \mathrm{ml})$. The sample was sonicated for $30 \mathrm{~min}$, and then refluxed for $2 \mathrm{~h}$ and filtered (28). The residue was resuspended in $100 \mathrm{ml}$ of chloroform/methanol (1:1, vol/ vol), refluxed for $1 \mathrm{~h}$, and filtered. The combined extracts were taken to dryness on a rotary evaporator. The dried extract was resuspended in $80 \%$ methanol (1 $\mathrm{ml})$ by sonication, and the internal standard, nordeoxycholic acid $(5 \mu \mathrm{g})$ was added. The sample was diluted with $0.01 \mathrm{M}$ acetic acid $(19 \mathrm{ml})$ and passed through a column of Lipidex 1000 (bed size $4 \times 1 \mathrm{~cm}$; Packard Instrument Co., Groningen, The Netherlands). Aqueous acetic acid $(20 \mathrm{ml})$ was passed through the gel bed, followed by distilled water $(20 \mathrm{ml})$, and the combined effluent and washings were then passed through a Bond Elut- $\mathrm{C}_{18}$ cartridge and discarded. Bile acids were recovered by elution of the Lipidex 1000 column and the Bond Elut- $\mathrm{C}_{18}$ cartridge with methanol, 20 and $5 \mathrm{ml}$, respectively, and the combined extracts were taken to dryness.

Solvolysis, hydrolysis, ion-exchange chromatography, and derivatization steps. The methanolic extracts from the urine, serum, bile, and liver tissue were taken to dryness under a stream of nitrogen, and bile acid conjugates were solvolyzed (29) and enzymically hydrolyzed (30). After hydrolysis, bile acids were then extracted on a Bond Elut$\mathrm{C}_{18}$ cartridge and the unconjugated bile acids were isolated by lipophilic anion exchange chromatography on a column (bed size $0.6 \mathrm{~g}$ ) of diethylaminohydroxypropyl Sephadex LH-20 (Lipidex DEAP; Packard Instrument Co.) prepared in $72 \%$ ethanol and converted to the acetate form (31). Unconjugated bile acids were eluted with $0.1 \mathrm{~mol} /$ liter acetic acid in $72 \%$ ethanol $(7 \mathrm{ml})$, and converted to volatile methyl ester-trimethylsilyl (Me-TMS) ether derivatives (32) for analysis by GC-MS operated in repetitive scanning mode.

Urinary bile acid analysis by FAB-MS. Negative ion FAB-MS spectra of bile acid conjugates excreted in urine were obtained after placing $1 \mu \mathrm{l}$ of the methanolic extract of urine before hydrolysis of conjugates (equivalent to $20 \mu \mathrm{l}$ of the urine) onto a drop of a glycerol/ methanol (1:1, by vol) matrix spotted on a stainless steel probe. The probe was introduced into the ion source of a VG Autospec Q mass spectrometer (Fisons Instruments, Manchester, UK) and ionized by a beam of fast atoms of cesium $(35 \mathrm{keV})$ fired at the target containing the sample. Negative ion mass spectra were recorded over the mass range of $50-1,000 \mathrm{D}$.

$G C$-MS. Bile acid Me-TMS ethers were separated on a $30 \mathrm{~m} \times$ $0.25 \mathrm{~mm}$ i.d. DB- 1 capillary column using temperature programmed operation from 225 to $295^{\circ} \mathrm{C}$ with increments of $2^{\circ} \mathrm{C} / \mathrm{min}$, after initial and final isothermal periods of 2 and $20 \mathrm{~min}$, respectively. GC-MS was performed on a VG Autospec Q mass spectrometer operated in electron ionization $(70 \mathrm{eV})$ mode. Repetitive scanning was performed over the mass range of 50-800 D. The identification of a bile acid was based on its GC retention index from both the scan number and time, and ion current response at its characteristic mass (33). Bile acid concentrations in urine, serum, bile, and liver tissue were quantified by gas chromatography by comparing the peak height response with the response obtained for a known amount of the added internal standard, nordeoxycholic acid $(23,34)$.

\section{Biochemical enzyme assays}

Microsomal membranes were prepared from frozen human liver following a standard protocol of sequential centrifugation. Aliquots of liver tissue were Dounce-homogenized in 4 vol of ice-cold sucrose buffer (0.25 M sucrose, $1 \mathrm{mM}$ EDTA, $20 \mathrm{mM}$ Tris-Cl, pH 7.4, 9,000 trypsin IU/ml aprotinin, $10 \mu \mathrm{g} / \mathrm{ml}$ pepstatin, and $5 \mu \mathrm{M}$ phenylmethylsulfonyl fluoride). The homogenate was centrifuged for $10 \mathrm{~min}$ at $600 \mathrm{~g}$, the supernatant was transferred to fresh tubes and centrifuged for 15 $\min$ at $10,000 \mathrm{~g}$. The supernatant from this step was centrifuged for 30 min at 130,000 $\mathrm{g}$. Membrane pellets from the final centrifugation step were resuspended by homogenization in $50 \mathrm{mM}$ Tris-acetate $(\mathrm{pH}$ 7.4), $20 \%$ (vol/vol) glycerol, $1 \mathrm{mM}$ EDTA. Protein concentrations were determined using the BCA protein assay kit (Pierce, Rockford, IL).

Cholesterol $7 \alpha$-hydroxylase activity was assayed in the presence of $7 \mathrm{nmol}$ of $\left[{ }^{14} \mathrm{C}\right]$ cholesterol $(56 \mathrm{mCi} / \mathrm{mmol})$ in $0.5 \mathrm{ml}$ containing 50 $\mathrm{mM}$ Tris-acetate ( $\mathrm{pH} 7.4), 20 \%$ (vol/vol) glycerol, 1 mM EDTA, 2 $\mathrm{mM}$ dithiothreitol, $0.06 \%$ Triton X-100, $1.5 \mathrm{mM} \mathrm{NADPH}$, and $1 \mathrm{mg}$ of microsomal protein. Reactions were carried out for $30 \mathrm{~min}$ at $37^{\circ} \mathrm{C}$, followed by extraction with methylene chloride. The organic phase was taken to dryness under a stream of nitrogen gas. Lipids were redissolved in $50 \mu \mathrm{l}$ Folch reagent (chloroform/methanol 2:1 by vol) and subjected to thin layer chromatography in ethyl acetate/toluene (2:3 by vol). Radiolabeled products were quantified using a System 200 Imaging Scanner (Bioscan Inc., Washington, DC). For determination of oxysterol $7 \alpha$-hydroxylase activity, $0.06 \mathrm{nmol}\left[{ }^{3} \mathrm{H}\right] 25$-hydroxycholesterol $(80 \mathrm{Ci} / \mathrm{mmol})$ was incubated with $250 \mu \mathrm{g}$ of microsomal protein using the assay described above. Steroid $5 \alpha$-reductase type 1 activity was measured under the same conditions except that $\left[{ }^{14} \mathrm{C}\right]$ testosterone $(58 \mathrm{mCi} / \mathrm{mmol}$, final concentration $14 \mu \mathrm{M})$ was used as a substrate and the silica gel plates were developed in a solvent system containing chloroform/ethyl acetate ( $3: 1$ by vol). The detection limits for these enzymatic activities were $0.05-0.25 \mathrm{pmol} / \mathrm{min} / \mathrm{mg}$ cell protein for oxysterol $7 \alpha$-hydroxylase and steroid $5 \alpha$-reductase and $0.5-$ $2.0 \mathrm{pmol} / \mathrm{min} / \mathrm{mg}$ cell protein for cholesterol $7 \alpha$-hydroxylase.

\section{Genetic analysis}

cDNA and genomic clones encoding the human oxysterol $7 \alpha$-hydroxylase were isolated by hybridization screening. The exon/intron structure of the gene was deduced by DNA sequence analysis and comparison to the cDNA sequence. Chromosomal localizations of the oxysterol $7 \alpha$-hydroxylase and cholesterol $7 \alpha$-hydroxylase genes were performed using the Stanford G3 panel of radiation hybrid DNAs (Research Genetics, Huntsville, AL) and PCR. A mutation in the oxysterol $7 \alpha$-hydroxylase gene was identified by amplification of individual exons followed by DNA sequence analysis. The DNA sequence of the oligonucleotide primers and the thermocycler programs used to amplify exons are available upon request (D.W. Russell).

\section{cDNA expression}

Cultured monolayers of human embryonic 293 cells or Chinese hamster ovary cells were transfected using an MBS kit (Stratagene, La Jolla, CA). Oxysterol $7 \alpha$-hydroxylase enzyme activity was measured $24 \mathrm{~h}$ after transfection by the addition of $0.2 \mathrm{mM}\left[{ }^{3} \mathrm{H}\right] 25$-hydroxycholesterol to the culture media (22). After the indicated times of incubation, sterols were extracted from the media and analyzed by thin layer chromatography on silica plates. Activity was quantified by phosphorimaging. Experiments using 293 cells were carried out in the presence of $50 \mathrm{mM}$ nafimidone to inhibit an endogenous oxysterol $7 \alpha$-hydroxylase enzyme activity (22). Oxysterol $7 \alpha$-hydroxylase protein levels were estimated by immunoblotting as described elsewhere (22). Site-directed mutagenesis was performed using PCR. All modified cDNAs were subjected to DNA sequence analysis to confirm the absence of spurious mutations.

\section{Results}

\section{Pathology}

The initial liver biopsy (day 75 of life) showed a marked increase in portal connective tissue with bridging fibrosis and probable cirrhosis (Fig. $2 A$ ). There was mild portal inflammation mixed with residual extramedullary hematopoiesis, canalicular and bile duct bile plugging, and moderate lobular disarray with giant cell transformation (Fig. 2 B). Prominent bile duct 

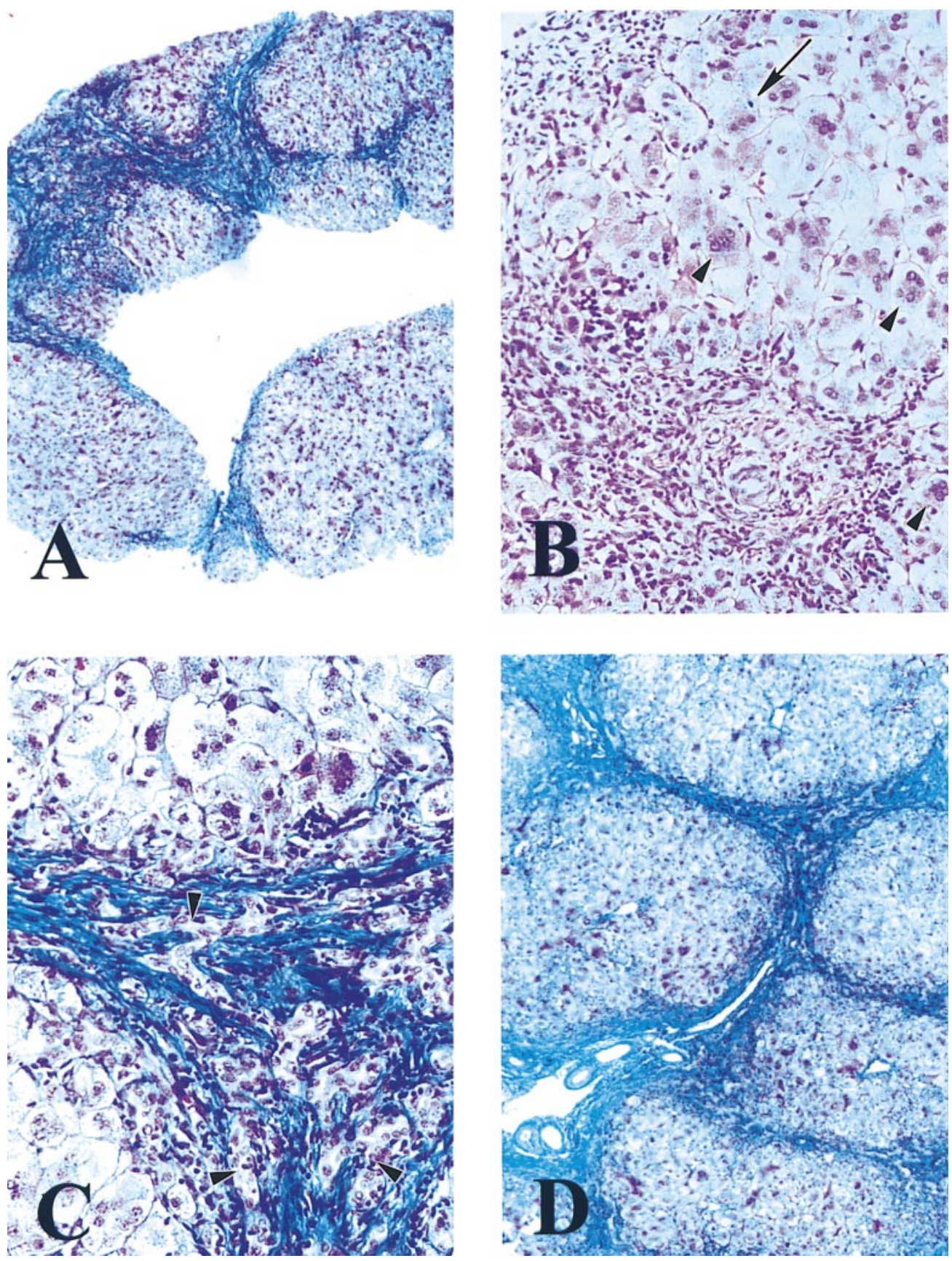

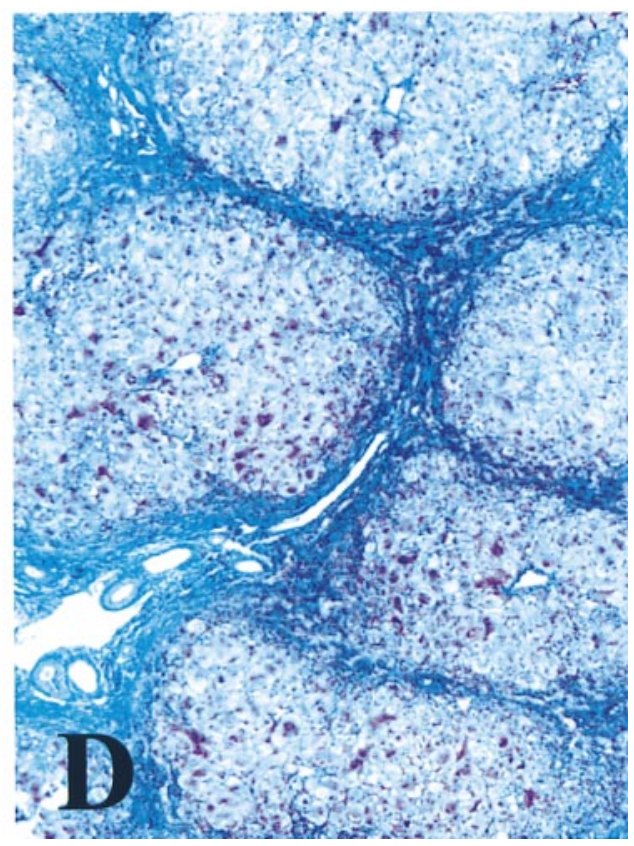

Figure 2. (A) Needle biopsy obtained at day 75 of life showing extensive portal fibrosis with nodules, and portal inflammation mixed with extramedullary hematopoiesis (trichrome, original magnification $\times 40)$. $(B)$ Higher power view of same biopsy showing multinucleated giant cell transformation (arrowheads) and canalicular bile stasis (arrow). The portal tract inflammation and fibrosis are also demonstrated (hematoxylin and eosin, original magnification $\times 200$ ). (C) Wedge biopsy of liver obtained at day 77 of life showing similar findings with bile duct proliferation (arrowheads) and portal fibrosis highlighted (trichrome, original magnification $\times 200)$. (D) Explanted liver, day 137 of life, showing regenerative nodules and extensive fibrosis (trichrome, original magnification $\times 100)$. proliferation was also noted suggesting an obstructive etiology (Fig. 2 C). No hepatocyte drop out, viral cytopathic changes, pseudoacinar change, evidence of alpha-1-antitrypsin disease, or obvious steatosis was seen.

At time of laparotomy (day 77 of life), a wedge liver biopsy was performed and showed findings identical to the needle biopsy; cirrhosis was confirmed with regenerative nodules seen. Ultrastructural evaluation showed enlarged and often multinucleated hepatocytes containing cytoplasmic bile. Canalicular bile did not have the appearance of that seen in Byler's disease. The mitochondria were normal in appearance and peroxisomes appeared increased in number but no structural abnormalities were identified. No metabolic storage product or viral particles were seen.

The explanted liver (day 137 of life) showed identical findings although there appeared to be hepatocytic damage due to the accumulating bile with occasional necrotic hepatocytes and patchy chronic inflammation seen (Fig. 2 D). Other than bile duct proliferation and bile plugging, the ducts appeared histologically normal, as did the gallbladder.

The posttransplant liver biopsy (day 149 of life) showed changes of moderate acute rejection with portal expansion by mononuclear inflammatory cells with bile duct involvement and portal and central vein endothelialitis. No bile plugging, cholestasis, or hepatocyte drop out was seen. Subsequent liver biopsy (day 151 of life) showed resolution of findings of rejection. After the onset of sepsis, a bone marrow biopsy was done to evaluate pancytopenia and showed left-shifted maturation but no evidence of significant hemophagocytosis or other abnormalities was seen. 
At autopsy (day 158) the large perineal ulcer with bacterial overgrowth was seen and felt to be the source of sepsis. There was third space fluid accumulation and an extensive lymphohistiocytic proliferative process involving the bone marrow, spleen, epicardium, meninges, and other soft tissues. The histology was that of Epstein-Barr virus-induced lymphoproliferative disease, and was confirmed by Eber in situ hybridization and PCR amplification. There was renomegaly with the kidneys weighing $\sim 2.5$ times the expected weight and grossly and histologically showed medullary cysts of varying sizes. This was the only organ system involved (other than the native liver) that may be related to the enzyme defect identified. No other developmental defects were seen.

\section{Biochemical identification of an inborn error in bile acid synthesis}

Urinary bile acid analysis. The negative ion mass spectrum of the urine from patient JC revealed a series of intense ions in the mass range corresponding to bile acids and their conjugates $(m / z, 350-700)$ and consistent with a severe cholestatic condition (Fig. 3). The major ions at $m / z 453$ and 510 were con-

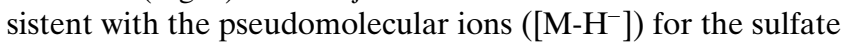
and glycosulfate conjugates, respectively, of monohydroxy- cholenoates $\left(\mathrm{C}_{24}\right.$ bile acids). The ion at $\mathrm{m} / \mathrm{z}, 480$ represents a corresponding taurine conjugate. Several other ions of unknown origin were also present. None of these ions are observed in mass spectra from the urine of normal infants of similar age, which typically show mainly ions derived from the glycerol matrix $(\mathrm{m} / \mathrm{z}, 367,459,551$, and 643) (Fig. 3, top). Subsequent analysis of the urine from both parents by FAB-MS was unrevealing; none of the major ions observed in the mass spectrum of the patient's urine were present in the mass spectra of the parents' urine (data not shown), which were indistinguishable from normal adult urine.

GC-MS analysis of the Me-TMS ether derivatives of bile acids isolated after solvolysis and hydrolysis of the urine sample (Fig. 4) revealed one major compound having a retention index of 32.00 methylene units (MU). The retention index and electron ionization $(70 \mathrm{eV})$ mass spectrum of this compound (Fig. 5) were found to be identical to that of the Me-TMS ether

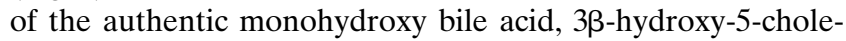
noic acid $(33,35-37)$. The molecular ion was $m / z$ 460, and consistent with a monohydroxy-unsaturated $\mathrm{C}_{24}$ bile acid. Prominent ions at $m / z 404$ [M-56], $m / z 331$ [M-129], the base peak, and $m / z, 129$ are all induced by the presence of a C-5,C-6 double bond in the steroid nucleus. The 129-D fragment consists

\section{\begin{tabular}{c} 
Patient JC - urine \\
oxysterol $7 \alpha$-hydroxylase deficiency \\
\hline
\end{tabular}}

unsaturated monohydroxy $\mathrm{C}_{24}$ sulfate
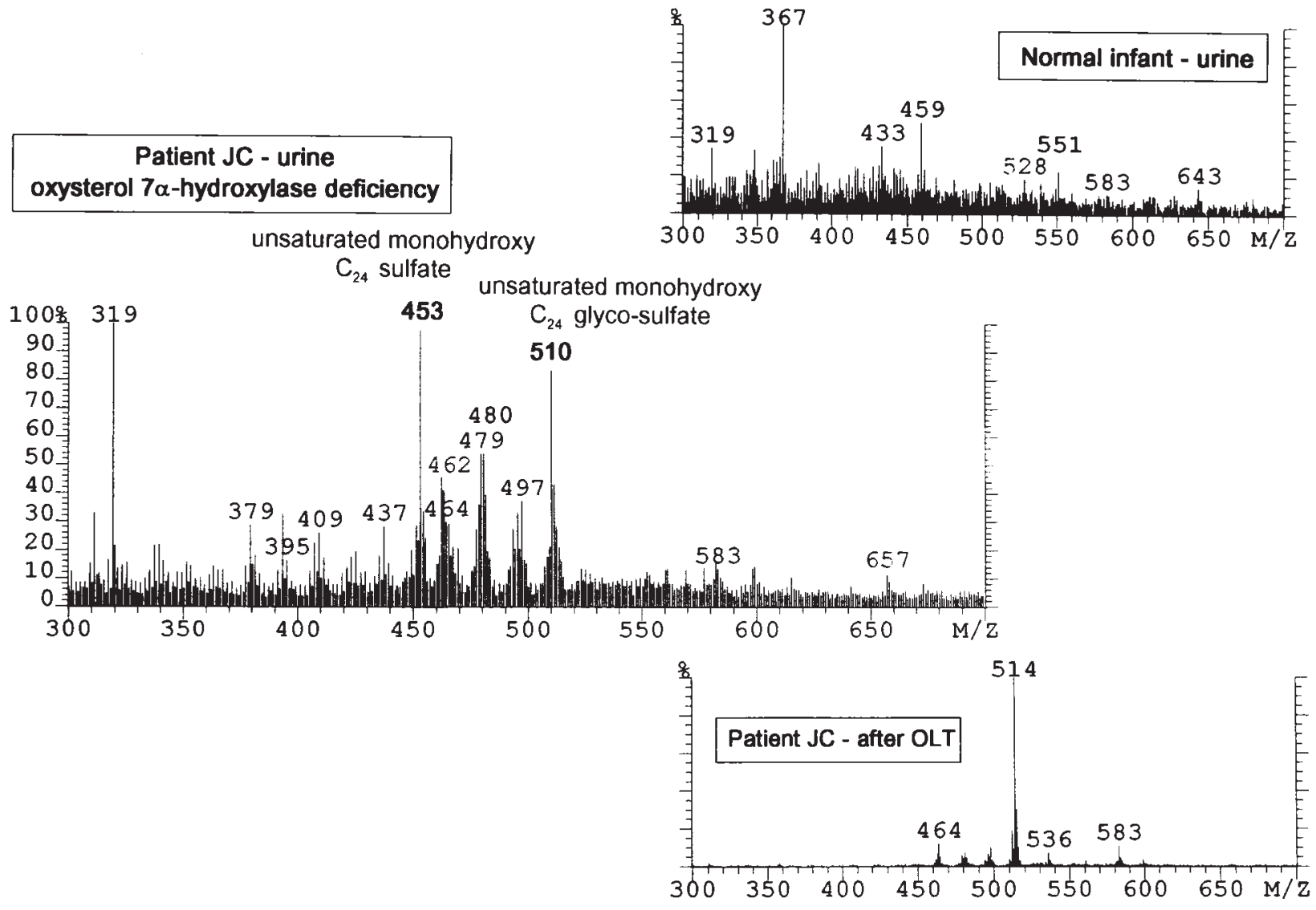

Figure 3. The negative ion FAB-MS mass spectrum (middle) of the urine sample from a 10-wk-old patient (JC) diagnosed with oxysterol $7 \alpha$ hydroxylase deficiency is compared with the corresponding mass spectrum from a normal infant of similar age (top). The mass spectrum of the urine from the patient after orthotopic liver transplantation $(O L T)$ is shown in the bottom panel. Ions corresponding to the sulfate and glycosulfate conjugates of the monohydroxylated bile acid, 3ß-hydroxy-5-cholenoic acid ( $\mathrm{m} / \mathrm{z} 453$ and $\mathrm{m} / \mathrm{z} 510$, respectively), are the signature metabolites for this inborn error in bile acid synthesis. The ion $\mathrm{m} / \mathrm{z} 514$ corresponds to taurine-conjugated trihydroxycholanoic acid due to the presence of the primary bile acid, cholic acid. This sample was obtained immediately after transplantation and reflects synthesis of cholic acid by the new liver and/or the washout of cholic acid that was administered to the patient in the period leading up to orthotopic liver transplantation. 

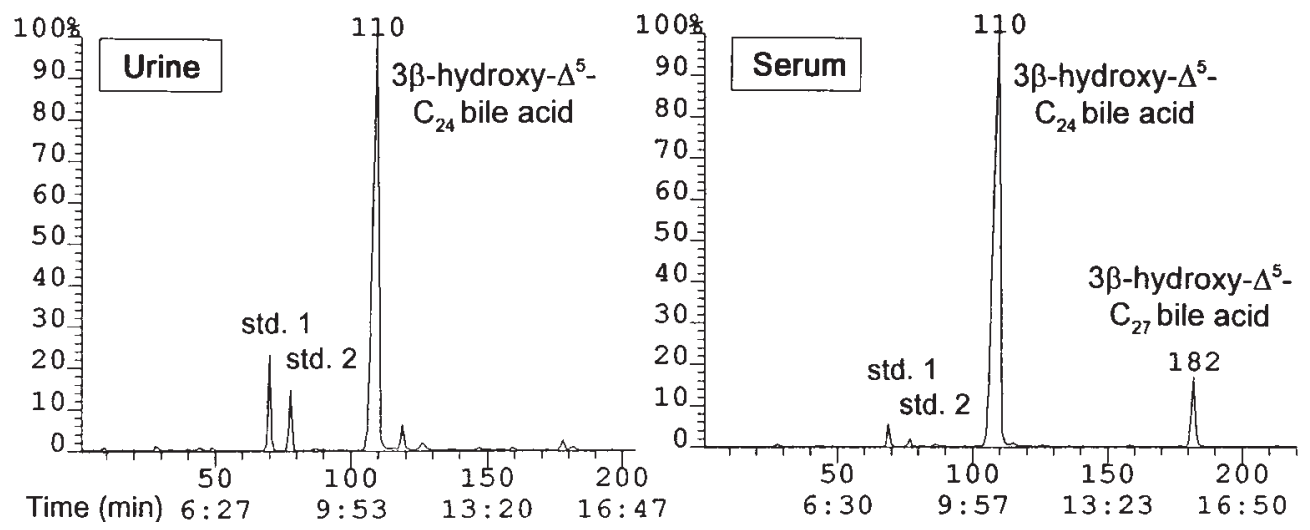

Figure 4. Total ion current chromatograms from the GC-MS analysis of the Me-TMS derivatives isolated after solvolysis and hydrolysis of bile acids in the urine and serum from a patient (JC) with oxysterol $7 \alpha$-hydroxylase deficiency. The major compounds with retention indices of 32.00 and $34.45 \mathrm{MU}$, respectively, were identified as derivatives of $3 \beta$-hydroxy-5-cholenoic and $3 \beta$-hydroxy-5-cholestenoic acids.

of C-1 to C-3 and 3-OTMS, while the 56-D loss involves the same carbon atoms but lacking the C-3-OTMS group. The ion at $m / z, 370$ [M-90] is formed from the loss of the trimethylsilanol group at C-3 from the molecular ion, while the ion at $\mathrm{m} / \mathrm{z}, 255$ arises from side chain cleavage (M-[90-115]). The urinary concentration of $3 \beta$-hydroxy-5-cholenoic acid was 14.0 $\mu \mathrm{mol} / \mathrm{liter}$ and this bile acid accounted for $77.6 \%$ of the total bile acids excreted in urine (Table I). Only trace amounts of cholic acid and chenodeoxycholic acids were identified in the urine. Additionally, there was no evidence for tetrahydroxylated bile acids that are typically excreted by normal neonates.

Serum bile acid analysis. The GC-MS total ion current chromatogram of the Me-TMS ether derivatives of bile acids isolated from the serum of the patient was remarkably similar to that of the urinary profile (Fig. 4). Two prominent peaks were present, the major one having a retention index of $32.00 \mathrm{MU}$ and an electron ionization-mass spectrum that was identical to $3 \beta$-hydroxy-5-cholenoic acid, the major urinary bile acid. An additional compound having a retention index of 34.45 MU gave an electron ionization $(70 \mathrm{eV})$ mass spectrum with a fragmentation pattern that had many of the features of $3 \beta$-hydroxy-5-cholenoic acid; however, the masses of many of the ions were higher by $42 \mathrm{D}$, suggesting the addition of $\left[-\mathrm{CH}_{2}-\mathrm{CH}_{2}-\mathrm{CH}_{2}\right]$ to the side chain, and consistent with the difference in mass between a $\mathrm{C}_{24}$ and a corresponding $\mathrm{C}_{27}$ bile acid structure. The molecular ion was at $m / z .502$ and the loss of a single trimethylsilanol function, accounting for the ion at $\mathrm{m} / z, 412$, confirmed a monohydroxy bile acid. Ions at $\mathrm{m} / \mathrm{z}$ 446 [M-56], $m / z, 373$ [M-129], and $m / z, 129$ establish the presence of a 3 -trimethylsiloxy- $\Delta^{5}$ structure. $\mathrm{A}_{8}$ side chain is evi-

Table I. Bile Acid Concentrations ( $\mu$ mol/liter or nmol/g) and Proportions (\%; Shown in Parentheses) in Urine, Serum, and Liver Tissue from a Patient with an Oxysterol $7 \alpha$-Hydroxylase Deficiency at Baseline, during Cholic Acid Therapy, and after Transplant, and in His Parents

\begin{tabular}{|c|c|c|c|c|c|c|c|}
\hline & $3 \beta-\mathrm{OH}-\Delta^{5}-\mathrm{C}_{24}$ & $3 \beta-\mathrm{OH}-\Delta^{5}-\mathrm{C}_{27}$ & CDCA & $\mathrm{CA}$ & Others & Total & $\%$ Mono-OH \\
\hline \multicolumn{8}{|l|}{ Urine $(\mu \mathrm{mol} /$ liter $)$} \\
\hline \multicolumn{8}{|l|}{ Patient JC: } \\
\hline Baseline & $14.0(76.9)$ & ND & $0.4(2.2)$ & $1.9(10.4)$ & $1.9(10.4)$ & 18.2 & 76.9 \\
\hline Day 2 therapy & $19.9(24.8)$ & ND & $0.2(0.2)$ & $47.8(59.5)$ & $12.6(15.7)$ & 80.4 & 24.8 \\
\hline Day 4 therapy & $5.0(7.2)$ & ND & $0.3(0.4)$ & $54.1(77.3)$ & $10.9(15.5)$ & 70.3 & 7.1 \\
\hline Day 24 therapy & $21.4(6.6)$ & ND & ND & $234.7(72.0)$ & $69.9(21.4)$ & 326.0 & 6.6 \\
\hline Day 45 therapy & $23.9(12.4)$ & ND & ND & $152.9(79.4)$ & $15.9(8.3)$ & 192.7 & 12.4 \\
\hline After transplant & $11.1(5.6)$ & ND & $3.9(1.9)$ & $165.1(82.8)$ & $19.4(9.7)$ & 199.5 & 5.6 \\
\hline \multicolumn{8}{|l|}{ Parents: } \\
\hline Mother & $1.5(14.5)$ & ND & $0.5(5.4)$ & $0.3(2.5)$ & $7.7(77.0)$ & 10.0 & 15.0 \\
\hline Father & $0.4(5.9)$ & ND & $0.5(7.8)$ & $0.3(4.0)$ & $5.7(82.6)$ & 6.9 & 5.8 \\
\hline \multicolumn{8}{|l|}{ Serum ( $\mu \mathrm{mol} /$ liter $)$} \\
\hline \multicolumn{8}{|l|}{ Patient JC: } \\
\hline Baseline & $86.5(72.5)$ & $23.9(20.0)$ & $3.0(2.5)$ & $1.5(1.3)$ & $4.4(3.7)$ & 119.2 & 92.6 \\
\hline Day 2 therapy & $97.1(66.5)$ & $20.8(14.2)$ & $2.9(2.0)$ & $21.5(14.7)$ & $3.8(2.6)$ & 146.1 & 80.7 \\
\hline Day 4 therapy & $86.5(75.0)$ & $17.3(14.8)$ & $2.3(2.0)$ & $6.6(5.6)$ & $4.2(3.6)$ & 116.9 & 88.8 \\
\hline Day 45 therapy & $66.0(57.6)$ & $4.2(3.7)$ & $2.3(2.0)$ & $40.5(35.4)$ & $1.5(1.3)$ & 114.5 & 61.3 \\
\hline \multicolumn{8}{|l|}{ Parents: } \\
\hline Mother & ND & ND & $0.8(19.1)$ & $0.3(6.9)$ & $1.9(44.2)$ & 3.0 & 0.00 \\
\hline Father & ND & ND & $2.1(43.3)$ & $1.2(23.6)$ & $0.9(18.4)$ & 4.2 & 0.00 \\
\hline \multicolumn{8}{|l|}{ Liver tissue $(\mathrm{nmol} / \mathrm{g})$} \\
\hline \multicolumn{8}{|l|}{ Patient JC: } \\
\hline At transplant & $17.3(22.7)$ & $1.5(2.0)$ & $1.9(2.5)$ & $50.1(65.8)$ & $5.3(7.0)$ & 76.1 & 24.7 \\
\hline
\end{tabular}




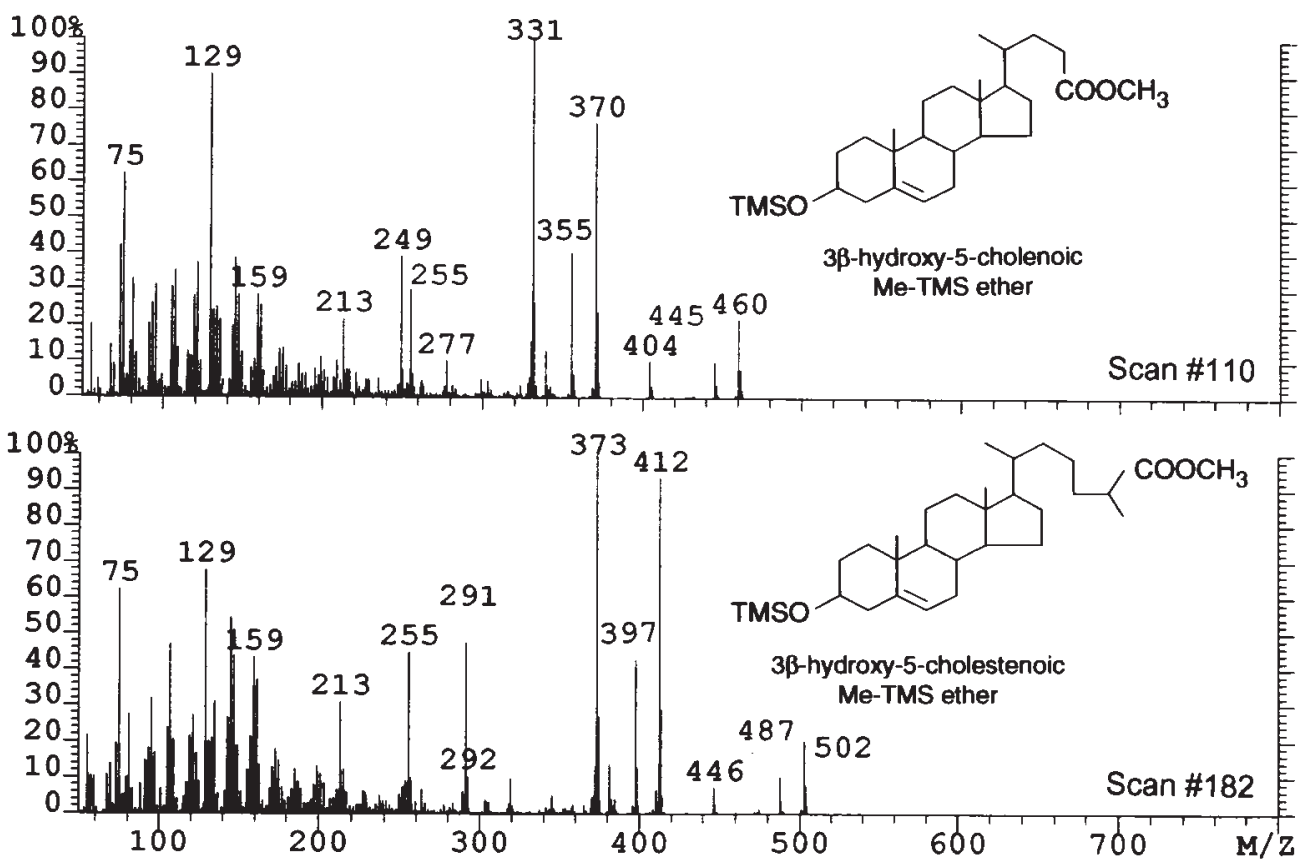

Figure 5. The electron $(70 \mathrm{eV})$ ionization-mass spectra of the major compounds having retention indices of $32.00 \mathrm{MU}$ (scan $110)$, identified in the urine and serum as the Me-TMS derivative

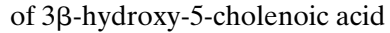
(top), and 34.45 MU (scan 182), identified in serum as $3 \beta$-hydroxy5-cholestenoic acid (bottom).

dent from the loss of $157 \mathrm{D}$ which gives rise to the ion at $\mathrm{m} / \mathrm{z}$ 255 (M-[90-157]); this represents the ABCD ring structure after loss of both the side chain and trimethylsiloxy group. The ion at $m / z, 291$ represents the intact side chain and C/D rings, and is analogous to the corresponding fragment at $m / z 249$ seen in the mass spectrum of the $\mathrm{C}_{24}$ equivalent structure (Fig. 5). The mass spectrum and GC retention index of this serum bile acid were identical to that of $3 \beta$-hydroxy-5-cholestenoic acid $(38,39)$.

Total serum bile acid concentration was $114.9 \mu \mathrm{mol} / \mathrm{liter}$, which was markedly elevated (upper limit of normal $3.5 \mu \mathrm{mol} /$ liter) and consistent with a severe cholestatic condition (Table I). The $3 \beta$-hydroxy- $\Delta^{5}$ bile acids collectively accounted for $96 \%$ of identifiable serum bile acids. As with urine, low concentrations of cholic and chenodeoxycholic acids were present (Fig. 6).

Biliary bile acids. Bile obtained at the time of exploratory laparotomy was analyzed by FAB-MS. The negative ion mass spectrum showed a weak signal at $\mathrm{m} / \mathrm{z}, 453$ corresponding to $3 \beta$-hydroxy-5-cholenoic acid sulfate. There was no evidence for canalicular secretion of primary bile acids. Several prominent ions were present consistent with the pseudomolecular ions and sodium adducts of sulfate and glucuronide conjugates of neutral sterols (data not shown). However, this fraction was not analyzed by GC-MS.

Neutral sterols in urine and serum. The neutral sterol fractions of the baseline urine and serum samples after conversion to the trimethylsilyl ether derivatives were analyzed by GCMS (Fig. 7). Both chromatograms show a conspicuous and major component that was identified from its electron ionization-mass spectrum (Fig. 7) and retention index (34.73 MU) as 27-hydroxycholesterol. The mass spectrum of the TMS ether showed a molecular ion at $\mathrm{m} / z 546$ consistent with an unsaturated dihydroxylated $\mathrm{C}_{27}$ sterol. Ions at $\mathrm{m} / z$ 456 [M-90] and $m / z$ 417 [M-129] are induced by the presence of the 5-6 double bond. The ion at $m / z, 129$ represents a fragment consisting of the $\mathrm{C}-1$ to $\mathrm{C}-3$ bond and the 3 -OTMS group. The mass spec- trum was identical to authentic 27-hydroxycholesterol and was similar to that reported previously (40). A second prominent dihydroxy-sterol with a retention index of $34.00 \mathrm{MU}$ was definitively identified as 24-hydroxycholesterol $(40,41)$. Its mass spectrum (Fig. 7) revealed a molecular ion at $\mathrm{m} / z$ 546. Ions at $m / z 145$, the base peak, $m / z 159$, and the loss of $43 \mathrm{D}$ from the molecular ion $(\mathrm{m} / z, 503)$ are explained by the fragmentation along the side chain and are induced by the presence of a 24-OTMS group. This spectrum was identical to that reported by Gustafsson and Sjovall (40). Traces of 25-hydroxycholesterol were identified in serum. Several other polyhydroxylated sterols were found in serum and urine as evidenced from their mass spectrometric fragmentation patterns but no attempt was made to identify their exact structures. While there was evidence for cholesterol, $7 \alpha$-hydroxycholesterol could not be found in either the urine or serum, and there was no evidence for other $7 \alpha$-hydroxylated sterols in these samples. The con-

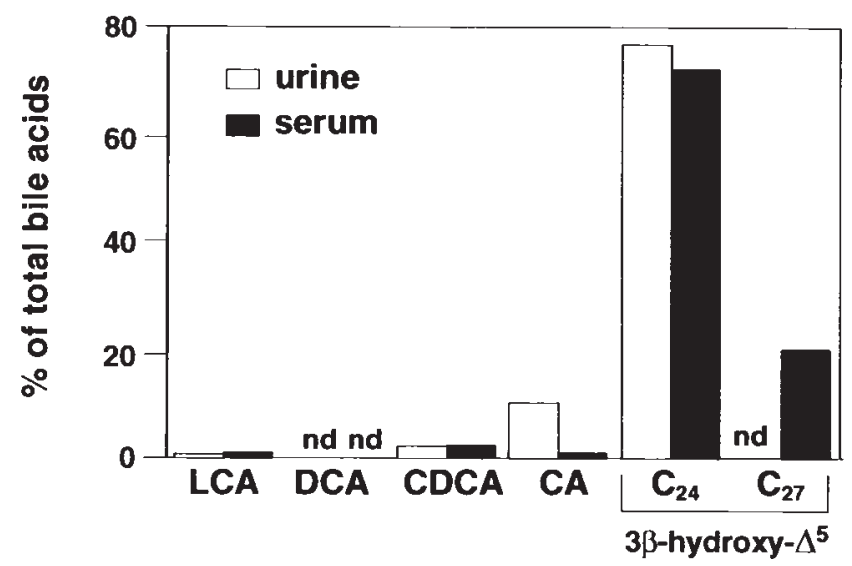

Figure 6. Relative proportions of bile acids in the serum and urine of a patient (JC) identified with oxysterol $7 \alpha$-hydroxylase deficiency. 


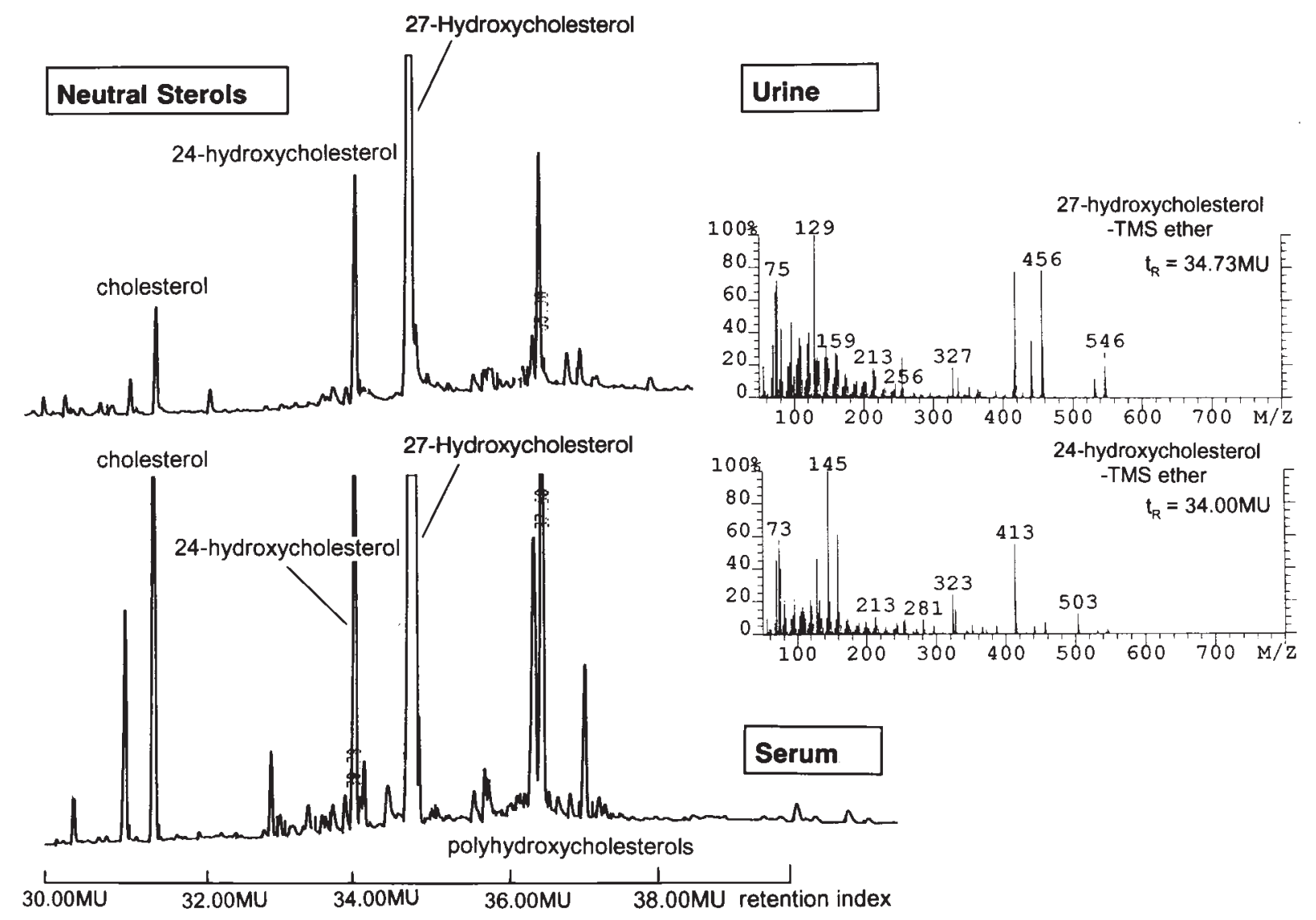

Figure 7. Chromatographic profiles obtained by gas chromatography of the trimethylsilyl ether derivatives of the neutral sterol fractions isolated from the serum and urine from a patient (JC) diagnosed with oxysterol $7 \alpha$-hydroxylase deficiency. Mass spectrometry confirmed 27 -hydroxycholesterol and 24-hydroxycholesterol (70 eV electron ionization-mass spectra of the TMS ethers shown) to be the major neutral dihydroxy-sterols, and there was no evidence for $7 \alpha$-hydroxylated sterols in these samples.

centrations of the major oxysterols in serum and urine are summarized in Table II.

Effect of oral bile acid therapy with cholic acid. Urine and serum were collected on days $2,4,24$, and 45 during the period the patient was undergoing oral bile acid therapy with cholic acid and before liver transplantation. The GC-MS profiles were similar to those obtained from the baseline analyses but with the additional presence of the exogenous cholic acid. There was very little change in the concentrations of $3 \beta$-hydroxy5-cholenoic and 3 $\beta$-hydroxy-5-cholestenoic acids (Fig. 8), indi- cating that cholic acid was ineffective in downregulating endogenous bile acid synthesis by feedback inhibition (42-44).

Liver tissue bile acids. Bile acids were measured by GCMS in a sample of liver tissue that was collected at the time of liver transplantation when the patient was undergoing oral bile acid therapy with cholic acid (Table I). Cholic acid was consequently the principal bile acid present, accounting for $69 \%$ of the total bile acids in the liver, and its concentration was 50 $\mathrm{nmol} / \mathrm{g}$. The concentration of $3 \beta$-hydroxy-5-cholenoic acid, the major endogenous bile acid identified in liver tissue, was 17.3

Table II. Concentrations of the Principal Oxysterols Identified in Serum and Urine from a Patient (JC) Identified with a Genetic Defect in Oxysterol $7 \alpha$-Hydroxylase

\begin{tabular}{lccc}
\hline & & Concentration (nmol/liter) \\
\cline { 2 - 4 } \multicolumn{1}{c}{ Sterol } & Serum & Normal serum values* $^{*}$ & Not detected \\
\hline 7 $\alpha$-Hydroxycholesterol & Not detected & $198 \pm 65$ & 3770 \\
24-Hydroxycholesterol & 151000 & $363 \pm 15$ & 175 \\
25-Hydroxycholesterol & 15484 & $22 \pm 2$ & 27600 \\
27-Hydroxycholesterol & 781000 & $586 \pm 10$ & 5550 \\
Polyhydroxycholesterols & 346700 & - & 37095 \\
Total oxysterols & 1278700 & - & Urine $^{\ddagger}$ \\
& & & \\
\hline
\end{tabular}

*Normal ranges for serum concentrations reported for healthy adults are taken from van Doormaal et al. (77) and Dzeletovic et al. (79) and are similar to values reported by others $(39,75,76,78)$. ${ }^{*}$ Determinations were made from a random spot urine sample. 

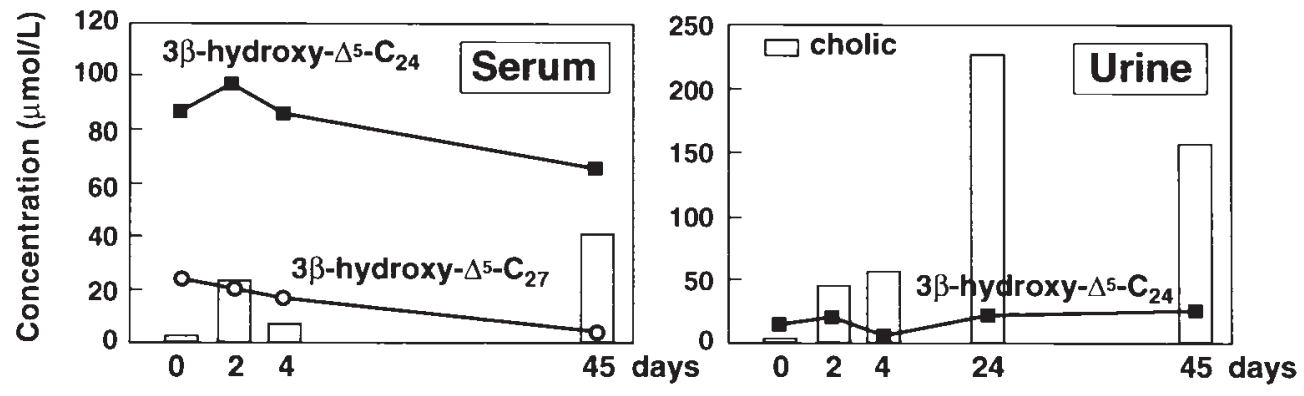

Figure 8. The effect of cholic acid therapy $(15 \mathrm{mg} / \mathrm{kg}$ body wt/d) on the concentrations of $3 \beta$ hydroxy-5-cholenoic and $3 \beta$ hydroxy-5-cholestenoic acid in the serum and urine from a patient with an oxysterol $7 \alpha-$ hydroxylase deficiency. The histogram depicts the concentrations of the exogenous cholic acid administered.

$\mathrm{nmol} / \mathrm{g}$ and it accounted for $24 \%$ of the total liver tissue bile acids. There were no other bile acids of significant concentration identified in the liver tissue.

Bile acid metabolism after liver transplantation. Bile and urine samples were obtained from the patient immediately after transplantation. The negative ion FAB-MS spectrum of the urine contrasts the corresponding pretransplantation spectrum of urine (Fig. 3, bottom) in that the characteristic ions at $\mathrm{m} / \mathrm{z}$, 453 and 510 for the conjugates of 3 $\beta$-hydroxy-5-cholenoic acid were absent. Ions for the primary bile acid conjugates $(\mathrm{m} / \mathrm{z}$ 514, taurocholate; $m / z$ 498, taurochenodeoxycholic; $m / z, 464$, glycocholate) were observed in the posttransplantation sample and reflect the elimination of the exogenous cholic acid administered up to the time of transplantation and the newly synthesized primary bile acids by the donor liver. The negative ion FAB-MS spectrum of the bile (data not shown) indicated normal canalicular secretion of the primary bile acid conjugates synthesized by the donor liver and no evidence for the atypical $3 \beta$-hydroxy- $\Delta^{5}$ bile acids or neutral sterols evident in fluids obtained before liver transplantation.

\section{Identification of an oxysterol $7 \alpha$-hydroxylase defect}

Biochemical measurement of $7 \alpha$-hydroxylase activity. Cholesterol $7 \alpha$-hydroxylase enzyme activity was not detectable in normal liver tissue from infants of $<1 \mathrm{yr}$ of age, or in the patient's liver. The absence of this activity was consistent with the lack of $7 \alpha$-hydroxycholesterol in the serum and urine of this individual and with earlier published studies (45). $7 \alpha$-Hydroxylated 25hydroxycholesterol was formed by membranes prepared from $1-, 2-$, and 6-mo control livers $(\mathrm{sp}$ act $=1.4-1.8 \mathrm{pmol} / \mathrm{min} / \mathrm{mg}$ protein), whereas there was no detectable oxysterol $7 \alpha$-hydroxylase activity in the patient's liver (Fig. 9). All specimens contained equal amounts of steroid $5 \alpha$-reductase type 1 enzyme activity (Fig. 9), a marker enzyme for tissue viability.

Molecular analyses of $7 \alpha$-hydroxylase genes. The biochemical data were consistent with a defect in either the cholesterol $7 \alpha$-hydroxylase gene (symbol $C Y P 7 A 1$ ) or the oxysterol $7 \alpha$ hydroxylase gene (symbol $C Y P 7 B 1$ ). To resolve this dichotomy, both genes were screened for the presence of inactivating mutations. The cholesterol $7 \alpha$-hydroxylase gene has been characterized previously and oligonucleotide primers for the amplification and analysis of individual exons of the gene have been reported (46). Analysis of the six exons of $C Y P 7 A 1$ in the proband's DNA by SSCP and DNA sequencing did not reveal any mutations in the coding region of the gene, suggesting that the underlying defect in this patient was not due to mutation of the cholesterol $7 \alpha$-hydroxylase gene.

Oxysterol $7 \alpha$-hydroxylase cDNAs encoding the rat and mouse enzymes have been reported (47); however, a cDNA for the human homologue had not been isolated, nor had the exon-intron structure of the gene or its chromosomal location been determined. To these ends, human oxysterol $7 \alpha$-hydroxylase cDNAs were isolated with a two-step strategy. Initially, degenerate primers from the mouse cDNA sequence were used to isolate a fragment of the human cDNA by RT-PCR using 293 cell mRNA as a template. This fragment was then used as a probe to screen commercially available human cDNA libraries to isolate a full-length copy of the mRNA. DNA sequence analysis and conceptual translation revealed a 506amino acid human oxysterol $7 \alpha$-hydroxylase (Fig. 10). The encoded protein is $66 \%$ and $65 \%$ identical in sequence to the mouse and rat enzymes, respectively. Transfection of the human cDNA into 293 cells resulted in a threefold increase over background of oxysterol $7 \alpha$-hydroxylase enzyme activity when 25-hydroxycholesterol or dehydroepiandrosterone was used as a substrate (data not shown). The $7 \alpha$-hydroxylated steroids from these reactions comigrated in two different solvent systems with the products synthesized from these substrates by an expressed murine oxysterol $7 \alpha$-hydroxylase whose chemical identities were confirmed $(21,22)$. The shared sequence identities, enzymatic properties, and gene structure and linkage (see below) indicated that the isolated human cDNA encoded a homologue of the rodent oxysterol $7 \alpha$-hydroxylase.

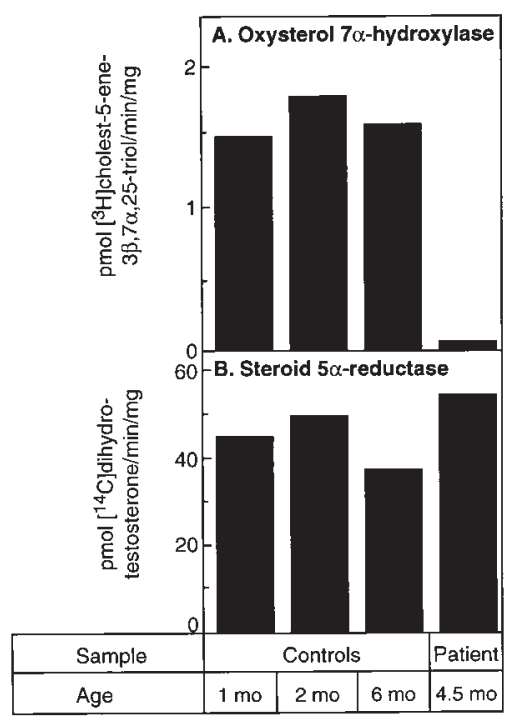

Figure 9. Measurement of oxysterol $7 \alpha$-hydroxylase and steroid $5 \alpha-$ reductase type 1 activity in liver membranes. Microsomal membrane proteins $(250 \mu \mathrm{g})$ were incubated with $\left[{ }^{3} \mathrm{H}\right] 25$ hydroxycholesterol $(A)$ or $\left[{ }^{14} \mathrm{C}\right]$ testosterone $(B)$ and the conversions of these substrates into $\left[{ }^{3} \mathrm{H}\right]$ cholest-5-ene$3 \beta, 7 \alpha, 25$-triol and $\left[{ }^{14} \mathrm{C}\right]$ dihydrotestosterone, respectively, were determined in duplicate by thin layer chromatography. The mean activities derived from two experiments are shown. Oxysterol $7 \alpha-$

hydroxylase activity was detected in the control samples from individuals of age 1,2 , and $6 \mathrm{mo}$, but not in the patient's liver $(A)$. All samples contained similar amounts of steroid $5 \alpha$-reductase type 1 activity $(B)$. 
Screening of bacteriophage lambda libraries produced the human $C Y P 7 B 1$ gene. Southern blotting and DNA sequence analysis of the genomic DNA and comparison to the cDNA revealed a gene composed of six exons (Fig. 10). The positions of the five introns were identical to those of the cholesterol $7 \alpha-$ hydroxylase gene. Both genes were positioned on the human chromosome complement by PCR analysis of radiation hybrid panel DNAs. In agreement with previous mapping data (46), CYP7A1 was localized to chromosome $8 \mathrm{q} 21.13$, closely linked $($ LOD score $=1,000)$ to the D8S1113 marker. Additional experiments showed that $C Y P 7 B 1$ was localized to chromosome $8 \mathrm{q} 21.3$, closely linked $($ LOD score $=9.7, \mathrm{cR}$ value $=21.12)$ to the D8S1473 marker. The close linkage of the genes encoding cholesterol and oxysterol $7 \alpha$-hydroxylase and their shared exon-intron structures suggest that they arose via an ancient duplication event.

To screen for mutations in the patient's oxysterol $7 \alpha$ hydroxylase gene, oligonucleotide pairs were used to amplify individual exons. Each DNA was then subjected to DNA sequence analysis. As shown in Fig. 11, the patient was homozygous for a cytosine to thymidine transition mutation in exon 5 that converted an arginine codon at position 388 to a nonsense codon (R388*). His mother (Fig. 11) and father (not shown) were heterozygous for this nonsense mutation. The R388* mutation was not detected in 16 unrelated healthy Mexican subjects and has not been found in any other control DNAs.

To confirm that the nonsense mutation abolished oxysterol $7 \alpha$-hydroxylase enzyme activity, the mutation was reproduced in an expressible mouse cDNA using site-directed mutagenesis. The mouse oxysterol $7 \alpha$-hydroxylase was used in these ex-

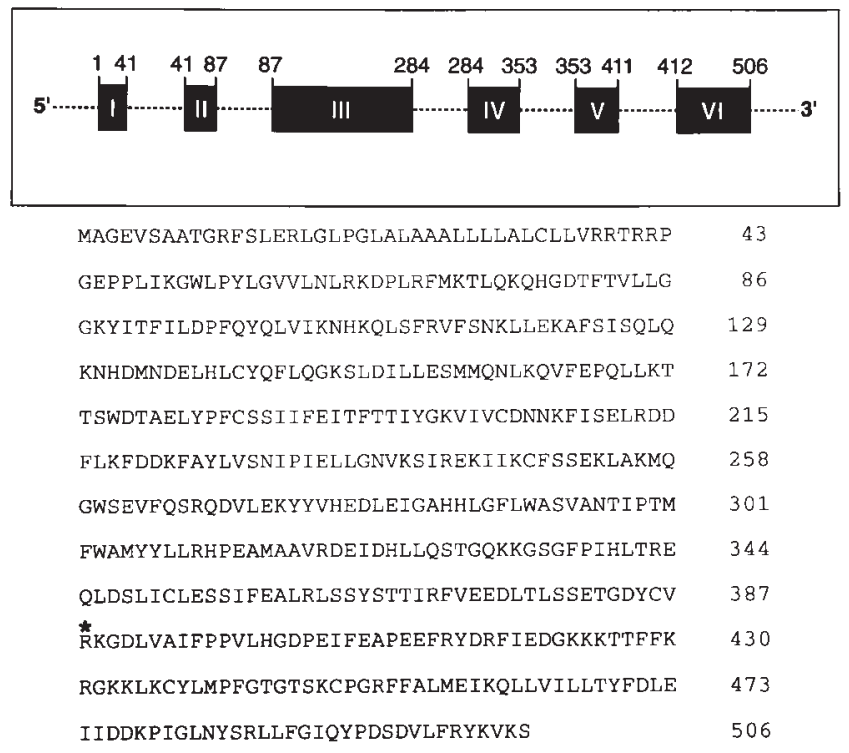

Figure 10. Molecular analysis of the oxysterol $7 \alpha$-hydroxylase gene. The amino acid sequence of the enzyme as deduced from translation of the cDNA is shown in a single letter code. Amino acids are numbered on the right with position 1 assigned to the initiator methionine. An asterisk marks the location of the mutation at residue 388 . The accession number for the cDNA sequence is AF029403. The predicted structure of $C Y P 7 B 1$ is shown with exons indicated by boxes and introns by connecting lines. Exons are assigned Roman numerals and drawn to scale. The $5^{\prime}$ - and $3^{\prime}$-flanking regions of the gene and the introns are not drawn to scale. Amino acids encoded by individual exons are indicated above the boxes.

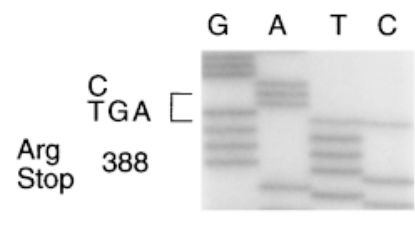

Parent

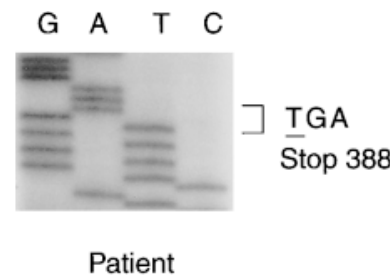

Figure 11. Amplification and sequencing by the dideoxyterminator method of exon 5 of the oxysterol $7 \alpha$-hydroxylase gene from the genomic DNAs of the patient and his mother. A transition mutation $(\mathrm{C} \rightarrow \mathrm{T})$ producing a premature termination codon ( $\mathrm{R} 388 \rightarrow \mathrm{Stop})$ is present in the heterozygous form in the mother (left) and in the homozygous form in the patient (right). The mutation occurred in a CG dinucleotide.

periments due to the availability of an antibody against the murine protein (22). Transfection of the normal murine cDNA into 293 cells produced easily detectable oxysterol $7 \alpha$-hydroxylase enzyme activity, whereas no activity was present in cells transfected with the cDNA containing the R388* mutation (Fig. 12). Immunoblot analysis showed that equal amounts of normal and truncated protein were present in the transfected cells (Fig. 12, inset). Similar results were obtained when the normal and mutant cDNAs were analyzed by transfection in Chinese hamster ovary cells (data not shown).

\section{Discussion}

Mammals dispose of cholesterol principally by converting it into $7 \alpha$-hydroxylated bile acids that are secreted in the bile (10). The classical pathway of bile acid synthesis is initiated by

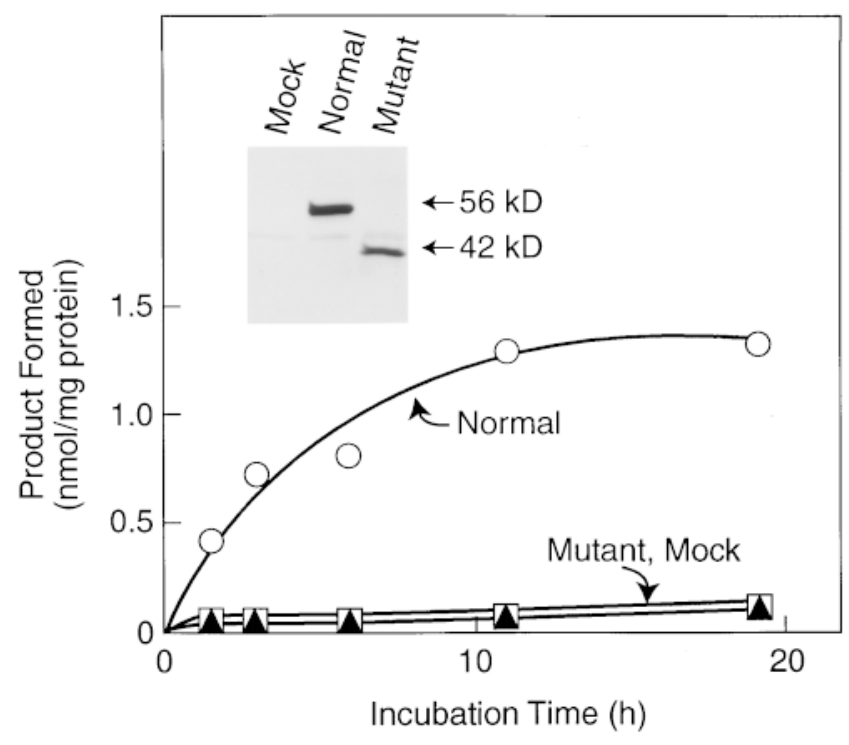

Figure 12. Expression of the normal and mutant oxysterol $7 \alpha$-hydroxylases. cDNAs encoding the normal murine cDNA or a version carrying the R388Stop mutation were inserted into a pCMV expression vector and transfected into 293 cells. The ability of the expressed proteins to convert $\left[{ }^{3} \mathrm{H}\right] 25$-hydroxycholesterol into $7 \alpha, 25$-dihydroxycholesterol was monitored by thin layer chromatography and expressed as a function of the incubation time. The levels of normal and mutant proteins present in the transfected cells after a 1.5 -h incubation were determined by immunoblotting (inset). 


\section{Biochemical basis for defect in oxysterol $7 \alpha$-hydroxylase}

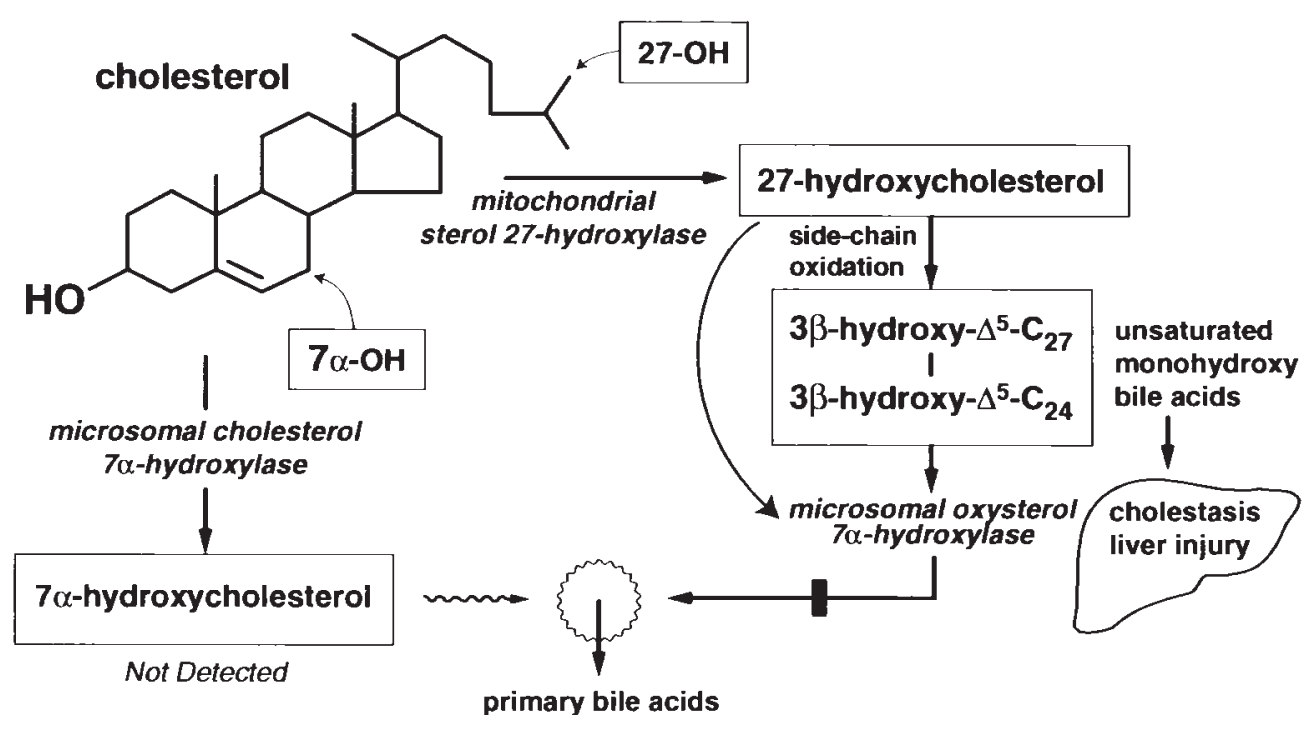

Figure 13. The two major pathways for primary bile acid synthesis from cholesterol depicting the biochemical presentation of a deficiency in oxysterol $7 \alpha$ hydroxylase as a cause of severe neonatal cholestatic liver disease. cholesterol 7 $\alpha$-hydroxylase (EC 1.14.13.17), a cytochrome P-450 enzyme of liver microsomes (48) (Fig. 13). The resultant $7 \alpha$-hydroxycholesterol undergoes further hydroxylations and oxidoreduction, followed by side-chain cleavage to form the primary bile acids, cholic and chenodeoxycholic acids (10). An alternative pathway, referred to as the acidic pathway (14-20), has been described in which cholesterol is first hydroxylated in the side chain by a mitochondrial sterol 27-hydroxylase (EC 1.14.13.15) that is also localized in extrahepatic tissues including, brain $(49,50)$, arterial endothelium $(51)$, and fibroblasts (52), and the product, 27-hydroxycholesterol, is further hydroxylated at the C-7 $\alpha$ position by an oxysterol $7 \alpha$-hydroxylase that resembles, but is distinct from, the cholesterol $7 \alpha$-hydroxylase of the classical pathway $(16,18,22,53)$. In mice, the physiologic relevance of the alternative pathway was established by the finding that adult mice homozygous for a knockout of the cholesterol $7 \alpha$-hydroxylase gene produced $7 \alpha$-hydroxylated bile acids, apparently as a result of this alternative pathway (21). In the rat, under conditions of complete repression of cholesterol $7 \alpha$-hydroxylase by continuous infusion of squalestatin, bile acid synthesis after $24 \mathrm{~h}$ was still $43 \%$ of preinfusion levels, indicating that the alternative pathway may account for almost half of the total bile acid synthesis (20). Precursor studies in humans indicate that the acidic pathway synthesizes $\sim 50 \%$ of the total bile acids (14). In adult patients with liver diseases, when bile acid synthesis is reduced (54-57), concentrations of cholestenoic acids are elevated (58), which also suggests that the alternative pathway is a significant contributor to bile acid synthesis in humans.

Here, we describe an infant with severe neonatal cholestasis whose biological fluids were virtually devoid of $7 \alpha$-hydroxylated bile acids due to a mutation in the gene encoding oxysterol $7 \alpha$-hydroxylase. In addition to establishing a further inborn error in bile acid synthesis as a cause of cholestatic liver disease, these observations demonstrate the quantitative importance of the acidic pathway for bile acid synthesis in human fetal and neonatal life. The infant, a 10-wk-old Mexican offspring of a first cousin marriage presented with progressive jaundice, elevated concentrations of serum liver enzymes, and a prolonged prothrombin time due in part to vitamin $\mathrm{K}$ malabsorption. Interestingly, there was a normal serum $\gamma$-glutamyltranspeptidase concentration, which has been shown previously to be highly associated with, although not exclusive to, patients with inborn errors in bile acid synthesis (59), since it is also a feature of Byler's disease, a condition of progressive familial intrahepatic cholestasis (60-62). A liver biopsy and histological analysis revealed diffuse syncytial giant cell transformation of hepatocytes with associated bile ductule proliferation and fibrosis (Fig. 2) and the histologic appearance resembled that observed in other inborn errors in bile acid synthesis $(3,4,11,63)$.

The diagnosis of a specific defect in $7 \alpha$-hydroxylation was established by FAB-MS analysis of the urine, which revealed a mass spectrum characterized by the absence of the normal primary bile acid conjugates and the presence of a series of unusual bile acids having molecular weights characteristic of unsaturated monohydroxylated bile acid conjugates. These were confirmed by GC-MS analysis to be monohydroxy bile acids with a $3 \beta$-hydroxy- $\Delta^{5}$ structure, and in common with most steroids with this nuclear structure, these metabolites are preferentially sulfated in the liver $(64,65)$. The $3 \beta$-hydroxy- $\Delta^{5}$ bile acids constituted $>90 \%$ of the serum bile acids and $>75 \%$ of the urinary bile acids. These metabolites also accounted for $24 \%$ of the liver tissue bile acids even during exogenous cholic acid therapy (Table I). 3 $\beta$-Hydroxy-5-cholenoic acid is a normal constituent of amniotic fluid $(66,67)$ and meconium $(68)$ and is found in small proportions in normal adult urine (32). However, it is increased in the urine of infants with cholestatic liver disease $(35,69)$, although not to the extent observed in the patient reported here; furthermore, in contrast to our patient, high concentrations of cholic and chenodeoxycholic acids accompany the elevations in $3 \beta$-hydroxy-5-cholenoic acid. $3 \beta$-Hydroxy-5-cholenoic acid was also found in low concentrations in the urine, but not the serum of the parents, who both showed serum and urinary bile acid profiles that were similar to those of healthy adults.

The mechanism of liver injury in this patient is proposed to be due to the accumulation of high concentrations of hepato- 
toxic monohydroxy bile acids with the $3 \beta$-hydroxy- $\Delta^{5}$ structure (70). The cholestatic effects of these metabolites would be further exacerbated by the lack of primary bile acids, which would normally provide the essential driving force for bile flow. It has been demonstrated that the taurine conjugate of the dihydroxy bile acid, $3 \beta, 7 \alpha$-dihydroxy-5-cholenoic acid, a major bile acid synthesized by patients with liver disease due to a deficiency in $3 \beta$-hydroxy- $\mathrm{C}_{27}$-steroid dehydrogenase/ isomerase (3), is not transported in an ATP-dependent manner, and that it also inhibits the ATP-dependent transport of cholic acid across rat canalicular plasma membranes (71). The monohydroxy bile acid, tauro-3 $\beta$-hydroxy-5-cholenoic acid, is markedly cholestatic in the rat, reducing bile flow and cholesterol and phospholipid secretion in a dose-dependent manner $(70,72)$. It was shown to have an even greater cholestatic potency than its saturated analogue, taurolithocholic acid (72). The accumulation of monohydroxy bile acids may also injure the liver through the generation of oxidant stress (73). Contrary to the general assumption that sulfation of bile acids provides a protective mechanism against cholestasis, tauro- $3 \beta$ hydroxy-5-cholenoate sulfate proved still to be markedly cholestatic in the rat, albeit with a less pronounced effect than that seen with the nonsulfated analogue (72). The accumulation of $3 \beta$-hydroxy- $\Delta^{5}$ cholenoic and cholestenoic acids in the liver of this patient could also contribute to reduced cholic acid synthesis via downregulation of the classical pathway using cholesterol $7 \alpha$-hydroxylase. In this regard, infusion of $3 \beta$-hydroxy- $\Delta^{5}$ cholenoic acid reduces cholic acid synthesis in the rabbit (74).

Analysis of neutral sterol fractions of serum and urine from the patient revealed GC profiles that featured a prominence of a major oxysterol, identified by mass spectrometry as 27hydroxycholesterol; concentrations in serum $(314 \mu \mathrm{g} / \mathrm{ml}$ or 781 $\mu \mathrm{mol} / \mathrm{liter})$ were found to be $>4,500$-fold those reported for the mean values in normal adult serum $(39,75-79)$. In addition, evidence for other side chain hydroxylated sterols was obtained by mass spectrometry, including elevated concentrations of 24-hydroxycholesterol, whereas $7 \alpha$-hydroxycholesterol could not be identified in any of the samples analyzed. The lack of $7 \alpha$-hydroxylated bile acids and sterols implies a deficiency in the activity of either cholesterol $7 \alpha$-hydroxylase or oxysterol $7 \alpha$-hydroxylase (Fig. 13) and the biochemical presentation is consistent with a metabolic defect involving the

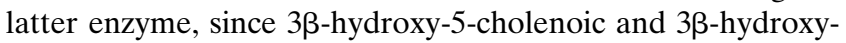
5 -cholestenoic acids can only be formed via the acidic pathway (Fig. 13), neither being good substrates for cholesterol $7 \alpha-$ hydroxylase (16). These intermediates would normally be hydroxylated by the oxysterol $7 \alpha$-hydroxylase to ultimately form chenodeoxycholic acid (80), although in the hamster they are less favorable substrates than 27-hydroxycholesterol for this enzyme (81). Interestingly, in this patient, the chenodeoxycholic acid concentration was only $6 \%$ of the level observed in normal human adult liver tissue (82). An oxysterol $7 \alpha$-hydroxylase defect is additionally supported by the finding of vast concentrations in serum and urine of 24-hydroxycholesterol, 25-hydroxycholesterol, and 27-hydroxycholesterol (Table II) which are substrates for oxysterol $7 \alpha$-hydroxylase. Given this biochemical and molecular presentation, this conclusion would imply that, in contrast to the mouse $(21,22)$, bile acid synthesis in early human development proceeds mainly via the acidic pathway and that cholesterol $7 \alpha$-hydroxylase is quantitatively of less importance in the human neonate. This interpretation would also explain the high concentration of $3 \beta$-hydroxy- 5-cholenoic acid in amniotic fluid $(66,67)$ and meconium $(68)$, and the predominance of chenodeoxycholic acid in human fetal bile $(83,84)$. As such, it is reasonable to assume that there may be species differences in the developmental expression of the two enzymes.

Measurements of hepatic $7 \alpha$-hydroxylase enzyme activities provided support for a defect in the oxysterol $7 \alpha$-hydroxylase. Thus, while no oxysterol $7 \alpha$-hydroxylase activity was detected in membranes isolated from the patient's liver, control livers from infants all had measurable activity of this enzyme (Fig. 9). Interestingly, cholesterol $7 \alpha$-hydroxylase activity was not detected in the liver samples from infants of $<1 \mathrm{yr}$ of age, including the patient's liver. This finding is supported by previous reports showing that cholesterol $7 \alpha$-hydroxylase enzyme activity is low to undetectable in human infant liver $(45,85)$. While a loss of cholesterol $7 \alpha$-hydroxylase enzyme activity might explain the lack of $7 \alpha$-hydroxylated bile acids, it would not account for the predominance of the $3 \beta$-hydroxy- $\Delta^{5}$ bile acids or the 27-hydroxycholesterol in this patient.

Unambiguous identification of the inborn error in bile acid synthesis in the patient subsequently came from molecular cloning studies which revealed a normal cholesterol $7 \alpha$-hydroxylase gene and a nonsense mutation (R388*) in the fifth exon of the oxysterol $7 \alpha$-hydroxylase gene (Fig. 10). This mutation was only detected in the patient and his parents. Truncation of the protein at this location is predicted to remove an essential cysteine residue (amino acid 449 in the normal protein, Fig. 10) that is conserved in all cytochrome P-450 enzymes and that normally forms a covalent bond with the essential heme cofactor (86). As expected, the truncated oxysterol $7 \alpha$-hydroxylase protein was inactive when expressed in cultured cells (Fig. 12).

Overall, these results demonstrate the importance of the oxysterol $7 \alpha$-hydroxylase enzyme to fetal and neonatal bile acid synthesis. A deficiency in the synthesis of $7 \alpha$-hydroxylated bile acids occurs in the neonatal period when this enzyme is absent, despite the presence of an apparently normal gene for cholesterol $7 \alpha$-hydroxylase. Failure to express cholesterol $7 \alpha-$ hydroxylase activity could be explained by some translational or posttranslational problem associated with the accumulation of large concentrations of oxysterols resulting from the mutation in the oxysterol $7 \alpha$-hydroxylase gene. Oxysterol $7 \alpha-$ hydroxylase deficiency thus represents a further inborn error in bile acid synthesis causing progressive neonatal intrahepatic cholestasis. More than 2,500 samples from cholestatic infants have been analyzed by mass spectrometry during the last $10 \mathrm{yr}$ in Cincinnati, and this is the first patient identified with a deficiency in $7 \alpha$-hydroxylation of bile acids. Given the relatively early age of the patient and the severity of the liver disease, it is possible that a mutation in the oxysterol $7 \alpha$-hydroxylase gene causes prenatal or early neonatal lethality, and that this case represents an exception to fetal death. However, with more widespread screening by mass spectrometry of neonates with advanced liver disease it is possible that the disorder may be more prevalent than the clinical screening has indicated so far. Clearly it is apparent that the oxysterol $7 \alpha$-hydroxylase is an important enzyme for protecting the liver from the toxicity of monohydroxy-bile acids synthesized exclusively through the acidic pathway (Fig. 13) as was proposed some years ago by Javitt (80), while it probably represents an important pathway for the regulation of cholesterol homeostasis $(19,49,52,87)$.

The prognosis for patients with an oxysterol $7 \alpha$-hydroxylase deficiency appears poor relative to those with other in- 
born errors in bile acid synthesis. Oral primary bile acid therapy, which has led to normalization in liver function and histology in most patients with liver disease due to deficiencies in 3 3 -hydroxy- $\mathrm{C}_{27}$-steroid dehydrogenase/isomerase (3) and $\Delta^{4}$-3-oxosteroid $5 \beta$-reductase (4), proved ineffective in this patient. Cholic acid administration in the previously described bile acid defects downregulates endogenous bile acid synthesis, leading to a virtual disappearance of the atypical hepatotoxic metabolites concomitant with clinical improvement $(1,2$, 11,12). This biochemical response did not occur in this patient, consistent with a lack in $7 \alpha$-hydroxylase activity and suggesting that cholic acid normally downregulates the expression of this gene (21). Consequently, it would appear that orthotopic liver transplantation may be the only therapeutic modality in the face of advancing liver disease due to hepatotoxicity from the accumulation of monohydroxy $3 \beta$-hydroxy- $\Delta^{5}$ bile acids produced as a consequence of the genetic defect in oxysterol $7 \alpha-$ hydroxylase.

\section{Acknowledgments}

We thank S. Nair for assistance with tissue culture, and M.S. Brown, J.L. Goldstein, and H.H. Hobbs for comments.

This research was supported by grants from the National Organization for Rare Disorders (to K.D.R. Setchell), the National Institutes of Health (R01DK38446 to R.J. Sokol, and HL20948 to D.W. Russell), the NIH National Centers for Research Resources (RR00069 to R.J. Sokol), the Deutsche Forschungsgemeinschaft (M. Schwarz), the Foundation BLANCEFLOR Boncompagni-Ludovisi, nee Bildt (E.G. Lund), the Medical Research Council (R. Lathe), and Biotechnology and Biological Sciences Research Council Funding to the Centre for Genome Research (R. Lathe).

\section{References}

1. Setchell, K.D.R., and N.C. O'Connell. 1994. Inborn errors of bile acid metabolism. In Liver Disease in Children. F.J. Suchy, editor. Mosby-Yearbook, Inc., St. Louis, MO. 835-851.

2. Setchell, K.D.R. 1996. Disorders of bile acid synthesis and metabolism. In Pediatric Gastrointestinal Disease. Pathophysiology, Diagnosis, Management. W.A. Walker, P.R. Durie, J.R. Hamilton, J.A. Walker-Smith, and J.A. Watkins, editors. B.C. Decker Inc., Toronto/Philadelphia. 1205-1233.

3. Clayton, P.T., J.V. Leonard, A.M. Lawson, K.D.R. Setchell, S. Andersson, B. Egestad, and J. Sjovall. 1987. Familial giant cell hepatitis associated with synthesis of $3 \beta, 7 \alpha$-dihydroxy- and $3 \beta, 7 \alpha, 12 \alpha$-trihydroxy-5-cholenoic acids. $J$. Clin. Invest. 79:1031-1038.

4. Setchell, K.D.R., F.J. Suchy, M.B. Welsh, L. Zimmer-Nechemias, J. Heubi, and W.F. Balistreri. 1988. $\Delta^{4}$-3-Oxosteroid $5 \beta$-reductase deficiency described in identical twins with neonatal hepatitis. A new inborn error in bile acid synthesis. J. Clin. Invest. 82:2148-2157.

5. Setoguchi, T., G. Salen, G.S. Tint, and E.H. Mosbach. 1974. A biochemical abnormality in cerebrotendinous xanthomatosis. Impairment of bile acid biosynthesis associated with incomplete degradation of the cholesterol side chain. J. Clin. Invest. 53:1393-1401.

6. Setchell, K.D.R., P. Bragetti, L. Zimmer-Nechemias, C. Daugherty, M.A. Pelli, R. Vaccaro, G. Gentilli, E. Distrutti, G. Dozzini, A. Morelli, and C. Clerici. 1992. Oral bile acid treatment and the patient with Zellweger syndrome. Hepatology. 15:198-207.

7. Clayton, P.T., M. Casteels, G. Mieli-Vergani, and A.M. Lawson. 1995. Familial giant cell hepatitis with low bile acid concentrations and increased urinary excretion of specific bile alcohols: a new inborn error of bile acid synthesis? Pediatr. Res. 37:424-431.

8. Clayton, P.T., A.W. Johnson, K.A. Mills, G.W. Lynes, J. Wilson, M. Casteels, and G. Mannaerts. 1996. Ataxia associated with increased plasma concentrations of pristanic acid, phytanic acid and $\mathrm{C}_{27}$ bile acids but normal fibroblast branched-chain fatty acid oxidation. J. Inherit. Metab. Dis. 19:761-768.

9. Setchell, K.D.R., J.E. Heubi, N.C. O'Connell, A.F. Hofmann, and J. Lavine. 1997. Identification of a unique inborn error in bile acid conjugation involving a deficiency in amidation. In Bile Acids in Hepatobiliary Disease: Basic and Clinical Applications. G. Paumgartner, A. Stiehl, and W. Gerok, editors. Kluwer Academic Publications, Dordrecht/Boston/London. 43-47.
10. Russell, D.W., and K.D.R. Setchell. 1992. Bile acid biosynthesis. Biochemistry. 31:4737-4739.

11. Daugherty, C.C., K.D.R. Setchell, J.E. Heubi, and W.F. Balistreri. 1993. Resolution of liver biopsy alterations in three siblings with bile acid treatment of an inborn error of bile acid metabolism $\left(\Delta^{4}\right.$-3-oxosteroid $5 \beta$-reductase deficiency). Hepatology. 18:1096-1101.

12. Ichimiya, H., H. Nazer, T. Gunasekaran, P. Clayton, and J. Sjovall. 1990. Treatment of chronic liver disease caused by $3 \beta$-hydroxy- $\Delta 5-\mathrm{C}_{27}$-steroid dehydrogenase deficiency with chenodeoxycholic acid. Arch. Dis. Child. 65:11211124 .

13. Setchell, K.D.R., and J.M. Street. 1987. Inborn errors of bile acid synthesis. Semin. Liver Dis. 7:85-99.

14. Axelson, M., and J. Sjovall. 1990. Potential bile acid precursors in plasma: possible indicators of biosynthetic pathways to cholic and chenodeoxycholic acids in man. J. Steroid Biochem. 36:631-640.

15. Axelson, M., J. Shoda, J. Sjovall, A. Toll, and K. Wikvall. 1992. Cholesterol is converted to $7 \alpha$-hydroxy-3-oxo-4-cholestenoic acid in liver mitochondria. Evidence for a mitochondrial sterol $7 \alpha$-hydroxylase. J. Biol. Chem. 267: 1701-1704.

16. Toll, A., J. Shoda, M. Axelson, J. Sjovall, and K. Wikvall. 1992. $7 \alpha-$ Hydroxylation of 26-hydroxycholesterol, 3ß-hydroxy-5-cholestenoic acid and $3 \beta$-hydroxy-5-cholenoic acid by cytochrome P-450 in pig liver microsomes. FEBS Lett. 296:73-76.

17. Martin, K.O., K. Budai, and N.B. Javitt. 1993. Cholesterol and 27hydroxycholesterol $7 \alpha$-hydroxylation: evidence for two different enzymes. $J$. Lipid Res. 34:581-588.

18. Shoda, J., A. Toll, M. Axelson, F. Pieper, K. Wikvall, and J. Sjovall 1993. Formation of $7 \alpha$ - and $7 \beta$-hydroxylated bile acid precursors from 27 hydroxycholesterol in human liver microsomes and mitochondria. Hepatology. 17:395-403.

19. Javitt, N.B. 1994. Bile acid synthesis from cholesterol: regulatory and auxiliary pathways. FASEB (Fed. Am. Soc. Exp. Biol.) J. 8:1308-1311.

20. Vlahcevic, Z.R., R.T. Stravitz, D.M. Heuman, P.B. Hylemon, and W.M. Pandak. 1997. Quantitative estimations of the contribution of different bile acid pathways to total bile acid synthesis in the rat. Gastroenterology. 113:949-957.

21. Schwarz, M., E.G. Lund, K.D.R. Setchell, H.J. Kayden, J.E. Zerwekh, I. Bjorkhem, J. Herz, and D.W. Russell. 1996. Disruption of cholesterol $7 \alpha-$ hydroxylase gene in mice. J. Biol. Chem. 271:18024-18031.

22. Schwarz, M., E.G. Lund, R. Lathe, I. Bjorkhem, and D.W. Russell. 1997. Identification and characterization of a mouse oxysterol $7 \alpha$-hydroxylase cDNA. J. Biol. Chem. 272:23995-24001.

23. Setchell, K.D.R., and A. Matsui. 1983. Serum bile acid analysis: the application of liquid-gel chromatographic techniques and capillary column gas chromatography and mass spectrometry. Clin. Chim. Acta. 127:1-17.

24. Setchell, K.D.R., D. Kritchevsky, and P.P. Nair. 1988. The Bile Acids. Chemistry, Physiology and Metabolism. Volume 4: Methods and Applications. Plenum Press, New York/London. 582 pp.

25. Setchell, K.D.R., and A.M. Lawson. 1989. Bile acids. In Mass Spectrometry. A.M. Lawson, editor. Walter deGruyter, Berlin/New York. 55-125.

26. Setchell, K.D.R., and J. Worthington. 1982. A rapid method for the quantitative extraction of bile acids and their conjugates from serum using commercially available reverse-phase octadecylsilane bonded silica cartridges. Clin. Chim. Acta. 125:135-144.

27. Rodrigues, C.M.P., and K.D.R. Setchell. 1996. Performance characteristics of reverse-phase bonded silica cartridges for serum bile acid extraction. Biomed. Chromatogr. 10:1-5.

28. Setchell, K.D.R., A.M. Lawson, N. Tanida, and J. Sjovall. 1983. General methods for the analysis of metabolic profiles of bile acids and related compounds in feces. J. Lipid Res. 24:1085-1100.

29. Hirano, Y., H. Miyazaki, S. Higashidate, and F. Nakayama. 1987. Analysis of 3-sulfated and nonsulfated bile acids by one-step hydrolysis and high performance liquid chromatography. J. Lipid Res. 28:1524-1529.

30. Nair, P.P., and C.C. Garcia. 1969. A modified gas-liquid chromatographic procedure for the rapid determination of bile acids in biological fluids. Anal. Biochem. 29:164-166.

31. Alme, B., A. Bremmelgaard, J. Sjovall, and P. Thomassen. 1977. Analysis of metabolic profiles of bile acids in urine using a lipophilic anion exchanger and computerized gas-liquid chromatography-mass spectrometry. J. Lipid Res. 18:339-362.

32. Blau, K., and G.S. King. 1979. Handbook of Derivatives for Chromatography. Heyden \& Son Ltd., London/Philadelphia/Rheine. 576 pp.

33. Lawson, A.M., and K.D.R. Setchell. 1988. Mass spectrometry of bile acids. In The Bile Acids. Volume 4: Methods and Applications. K.D.R. Setchell, D. Kritchevsky, and P.P. Nair, editors. Plenum Press, New York. 167-267.

34. Setchell, K.D.R. 1983. Liquid-solid extraction, lipophilic gel chromatography and capillary column gas chromatography in the analysis of bile acids from biological samples. In Bile Acids in Gastroenterology. L. Barbara, R.H Dowling, A.F. Hofmann, and E. Roda, editors. MTP Press Ltd., Lancaster/Boston/The Hague. 1-18.

35. Makino, I., J. Sjovall, A. Norman, and B. Strandvik. 1971. Excretion of $3 \beta$-hydroxy-5-cholenoic and $3 \alpha$-hydroxy- $5 \alpha$-cholanoic acids in urine of infants with biliary atresia. FEBS Lett. 15:161-164. 
36. Brooks, C.J.W., D.J. Harvey, B.S. Middleditch, and P. Vouros. 1973. Mass spectra of trimethylsilyl ethers of some $\Delta^{5}-3 \beta$-hydroxy $\mathrm{C}_{19}$ steroids. Org. Mass Spectrom. 7:925-948.

37. Bjorkhem, I., J.-A. Gustafsson, and J. Sjovall. 1973. A novel fragmentation of trimethylsilyl ethers of $3 \beta$-hydroxy- $\Delta^{5}$-steroids. Org. Mass Spectrom. 7: 277-281.

38. Parmentier, G.G., G.A. Janssen, E.A. Eggermont, and H.J. Eyssen. 1979. $\mathrm{C}_{27}$ bile acids in infants with coprostanic acidemia and occurrence of $3 \alpha, 7 \alpha, 12 \alpha$-trihydroxy- $5 \beta-\mathrm{C}_{29}$ dicarboxylic acid as a major component of their serum. Eur. J. Biochem. 102:173-183.

39. Axelson, M., B. Mork, and J. Sjovall. 1988. Occurrence of 3ß-hydroxy5-cholestenoic acid, $3 \beta, 7 \alpha$-dihydroxy-5-cholestenoic, and 7 $\alpha$-hydroxy-3-oxo4-cholestenoic acid as normal constituents in human blood. J. Lipid Res. 29: 629-641.

40. Gustafsson, J.-A., and J. Sjovall. 1969. Identification of 22-, 24- and 26hydroxycholesterol in the steroid sulphate fraction of faeces from infants. Eur. J. Biochem. 8:467-472.

41. Lund, E., I. Bjorkhem, C. Furster, and K. Wikvall. 1993. 24-, 25- and $27-$ hydroxylation of cholesterol by a purified preparation of 27-hydroxylase from pig liver. Biochim. Biophys. Acta. 1166:177-182.

42. Bergstrom, S., and H. Danielsson. 1958. On the regulation of the bile acid formation in the rat liver. Acta Physiol. Scand. 43:1-7.

43. Shefer, S., S. Hauser, I. Bekersky, and E.H. Mosbach. 1969. Feedback regulation of bile acid biosynthesis in the rat. J. Lipid Res. 10:404-411.

44. Danielsson, H. 1973. Influence of dietary bile acids on formation of bile acids in rat. Steroids. 22:667-676.

45. Gustafsson, J. 1986. Bile acid biosynthesis during development: hydroxylation of $\mathrm{C}_{27}$-sterols in human fetal liver. J. Lipid Res. 27:801-806.

46. Cohen, J.C., J.J. Cali, D.F. Jelinek, M. Mehrabian, R.S. Sparkes, A.J. Lusis, D.W. Russell, and H.H. Hobbs. 1992. Cloning of the human cholesterol $7 \alpha$-hydroxylase gene (CYP7) and localization to chromosome 8q11-q12. Genomics. 14:153-161.

47. Stapleton, G., M. Steel, M. Richardson, J.O. Mason, K.A. Rose, R.G.M. Morris, and R. Lathe. 1995. A novel cytochrome P450 expressed primarily in brain. J. Biol. Chem. 270:29739-29745.

48. Myant, N.B., and K.A. Mitropoulos. 1977. Cholesterol $7 \alpha$-hydroxylase. J. Lipid Res. 18:135-153.

49. Zhang, J., O. Larsson, and J. Sjovall. 1995. 7 $\alpha$-Hydroxylation of 25hydroxycholesterol and 27-hydroxycholesterol in human fibroblasts. Biochim. Biophys. Acta. 1256:353-359.

50. Zhang, J., Y. Akwa, E.-E. Baulieu, and J. Sjovall. 1995. 7 $\alpha$-Hydroxylation of 27-hydroxycholesterol in rat brain microsomes. C.R. Acad. Sci. Paris. 318:345-349.

51. Reiss, A.B., K.O. Martin, D.E. Rojer, S. Iyer, E.A. Grossi, A.C. Galloway, and N.B. Javitt. 1997. Sterol 27-hydroxylase: expression in human arterial endothelium. J. Lipid Res. 38:1254-1260.

52. Axelson, M., O. Larsson, J. Zhang, J. Shoda, and J. Sjovall. 1995. Structural specificity in the suppression of HMG-CoA reductase in human fibroblasts by intermediates in bile acid biosynthesis. J. Lipid Res. 36:290-298.

53. Martin, K.O., A.B. Reiss, R. Lathe, and N.B. Javitt. 1997. $7 \alpha-H y d r o x-$ ylation of 27-hydroxycholesterol: biologic role in the regulation of cholesterol synthesis. J. Lipid Res. 38:1053-1058.

54. Vlahcevic, Z.R., P. Juttijudata, C.C. Bell, Jr., and L. Swell. 1972. Bile acid metabolism in patients with cirrhosis. II. Cholic and chenodeoxycholic acid metabolism. Gastroenterology. 62:1174-1181.

55. McCormick, W.C., C.C. Bell, Jr., L. Swell, and Z.R. Vlahcevic. 1973. Cholic acid synthesis as an index of the severity of liver disease in man. Gut. 14: 895-902.

56. Stiehl, A., D.L. Earnest, and W.H. Admirand. 1975. Sulfation and renal excretion of bile salts in patients with cirrhosis of the liver. Gastroenterology. 68:534-544.

57. Engelking, L.R., S. Barnes, B.I. Hirschowitz, C.A. Dasher, J.G. Spenney, and D. Naftel. 1980. Determination of the pool size and synthesis rate of bile acids by measurements in blood of patients with liver disease. Clin. Sci. 58: 485-492.

58. Axelson, M., B. Mork, A. Aly, O. Wisen, and J. Sjovall. 1989. Concentrations of cholestenoic acids in plasma from patients with liver disease. J. Lipid Res. 30:1877-1882.

59. Setchell, K.D.R., D.A. Piccoli, N.C. O'Connell, E. Jacquemin, and O. Bernard. 1993. Progressive intrahepatic cholestasis with normal $\gamma$-glutamyltransferase is highly associated with the $3 \beta$-hydroxysteroid dehydrogenase/ isomerase deficiency, an inborn error in bile acid synthesis: a new category of metabolic liver disease. Hepatology. 18:178A. (Abstr.)

60. Clayton, R.J., F.L. Iber, B.H. Ruebner, and V.A. McKusick. 1969. Byler disease. Fatal familial intrahepatic cholestasis in an Amish kindred. Am. J. Dis. Child. 117:112-124.

61. Maggiore, G., O. Bernard, C.A. Reily, M. Hadchouel, A. Lemonnier, and D. Alagille. 1987. Normal serum $\gamma$-glutamyl-transpeptidase activity identifies groups of infants with idiopathic cholestasis with poor prognosis. J. Pediatr.
111:251-252.

62. Whitington, P.F., D.K. Freese, E.M. Alonso, S.J. Schwarzenberg, and H.L. Sharp. 1994. Clinical and biochemical findings in progressive familial intrahepatic cholestasis. J. Pediatr. Gastroenterol. Nutr. 18:134-141.

63. Witzleben, C.L., D.A. Piccoli, and K.D.R. Setchell. 1992. A new category of causes of intrahepatic cholestasis. J. Pediatr. Path. 12:269-274.

64. Hoshita, T. 1985. Bile alcohols and primative bile acids. In Sterols and Bile Acids. H. Danielsson and J. Sjovall, editors. Elsevier Science Publishers BV, Amsterdam. 279-302.

65. Takikawa, H., H. Otsuka, T. Beppu, and Y. Seyama. 1985. Determination of 3 $\beta$-hydroxy-5-cholenoic acid in serum of hepatobiliary diseases: its glucuronidated and sulfated conjugates. Biochem. Med. 33:393-400.

66. Deleze, G., G. Paumgartner, G. Karlaganis, W. Giger, M. Reinhard, and D. Sidiropoulos. 1978. Bile acid pattern in human amniotic fluid. Eur. J. Clin. Invest. 8:41-45.

67. Nakagawa, M., and K.D.R. Setchell. 1990. Bile acid metabolism in early life: studies of amniotic fluid. J. Lipid Res. 31:1089-1098.

68. Back, P., and K. Ross. 1973. Identification of 3ß-hydroxy-5-cholenoic acid in human meconium. Hoppe-Seyler's Z. Physiol. Chem. 354:83-89.

69. Javitt, N.B., E. Kok, M. Gut, I. Rajagopalan, and K. Budai. 1984. Neonatal cholestasis: identification of a metabolic error in bile acid synthesis. Pediatr. Res. 18(Suppl.):200A. (Abstr.)

70. Javitt, N.B., and S. Emerman. 1968. Effect of sodium taurolithocholate on bile flow and bile excretion. J. Clin. Invest. 47:1002-1014.

71. Steiger, B., J. Zhang, B. O'Neill, J. Sjovall, and P.J. Meier. 1997. Differential interaction of bile acids from patients with inborn errors of bile acid synthesis with hepatocellular bile acid transporters. Eur. J. Biochem. 244:39-44.

72. Mathis, U., G. Karlaganis, and R. Preisig. 1983. Monohydroxy bile salt sulfates: tauro-3 $\beta$-hydroxy-5-cholenoate-3-sulfate induces intrahepatic cholestasis in rats. Gastroenterology. 85:674-681.

73. Sokol, R.J., M.W. Devereaux, R.A. Khandwala, and K. O'Brien. 1993. Evidence for involvement of oxygen free radicals in bile acid toxicity to isolated rat hepatocytes. Hepatology. 17:869-881.

74. Hall, R., E. Kok, and N.B. Javitt. 1988. Bile acid synthesis: down-regulation by monohydroxy bile acids. FASEB (Fed. Am. Soc. Exp. Biol.) J. 2:152156.

75. Javitt, N.B., E. Kok, S. Burstein, B. Cohen, and J. Kutscher. 1981. 26 Hydroxycholesterol. Identification and quantitation in human serum. J. Biol. Chem. 256:12644-12646.

76. Koopman, B.J., J.C. Van Der Molen, B.G. Wolthers, and J.B. Vanderpas. 1987. Determination of some hydroxy-cholesterols in human serum samples. J. Chromatogr. 416:1-13.

77. van Doormaal, J.J., N. Smit, B.J. Koopman, J.C. van der Molen, B.G. Woolthers, and H. Doorenbos. 1989. Hydroxycholesterols in serum from hypercholesterolaemic patients with and without bile acid sequestrant therapy. Clin. Chim. Acta. 181:273-280.

78. Harik-Khan, R., and R.P. Holmes. 1990. Estimation of 26-hydroxycholesterol in serum by high-performance liquid chromatography and its measurement in patients with atherosclerosis. J. Steroid Biochem. 36:351-355.

79. Dzeletovic, S., O. Breuer, E. Lund, and U. Diczfalusy. 1995. Determination of cholesterol oxidation products in human plasma by isotope dilutionmass spectrometry. Anal. Biochem. 225:73-80.

80. Javitt, N.B., E. Kok, F. Carubbi, T. Blizzard, M. Gut, and C.Y. Byon. 1986. Bile acid biosynthesis. Metabolism of $3 \beta$-hydroxy-5-cholenoic acid to chenodeoxycholic acid. J. Biol. Chem. 261:12486-12489.

81. Lee, C., K. Martin, and N.B. Javitt. 1996. Bile acid synthesis: $7 \alpha$-hydroxylation of intermediates in the sterol 27-hydroxylase metabolic pathway. $J$. Lipid Res. 37:1356-1362.

82. Setchell, K.D.R., C.M.P. Rodrigues, C. Clerici, A. Solinas, A. Morrelli, C. Gartung, and J. Boyer. 1997. Bile acid concentrations in human and rat liver tissue and in hepatocyte nuclei. Gastroenterology. 112:226-235.

83. Colombo, C., G. Zuliani, M. Ronchi, J. Breidenstein, and K.D.R. Setchell. 1987. Biliary bile acid composition of the human fetus in early gestation. Pediatr. Res. 21:197-200.

84. Setchell, K.D.R., R. Dumaswala, C. Colombo, and M. Ronchi. 1988. Hepatic bile acid metabolism during early development revealed from the analysis of human fetal gallbladder bile. J. Biol. Chem. 263:16637-16644.

85. Collins, J.C., R.P. Altman, K.O. Martin, and N.B. Javitt. 1994. Bile acid synthesis in fetal and neonatal life: expression of cholesterol $7 \alpha$-hydroxylase and 27-hydroxycholesterol-7 $\alpha$-hydroxylase activities. Pediatr. Res. 35:126A. (Abstr.)

86. Hasemann, C.A., R.G. Kurumbail, S.S. Boddupalli, J.A. Peterson, and J. Deisenhofer. 1995. Structure and function of cytochromes P450: a comparative analysis of three crystal structures. Structure. 3:41-62.

87. Zhang, J., A. Dricu, and J. Sjovall. 1997. Studies on the relationships between $7 \alpha$-hydroxylation and the ability of 25- and 27-hydroxycholesterol to suppress the activity of HMG-CoA reductase. Biochim. Biophys. Acta. 1344:241249 